\title{
Pt Catalyst Degradation in Aqueous and Fuel Cell Environments studied via In-Operando Anomalous Small-Angle X-ray
}

\section{Scattering}

\author{
James A. Gilbert ${ }^{a}$, Nancy N. Kariuki ${ }^{b}$, Xiaoping Wang $^{b}$, A. Jeremy Kropf ${ }^{b}$, Kang Yu ${ }^{c}$, Daniel J. \\ Groom $^{c}$, Paulo J. Ferreira ${ }^{c}$, Dane Morgan ${ }^{a}$, and Deborah J. Myers ${ }^{b}$ \\ ${ }^{a}$ Department of Materials Science and Engineering University of Wisconsin-Madison, Madison, \\ WI 53706, USA \\ ${ }^{\mathrm{b}}$ Chemical Sciences and Engineering Division, Argonne National Laboratory, Lemont, IL 60439, \\ USA
}

${ }^{\mathrm{c}}$ Materials Science and Engineering Program, The University of Texas at Austin, TX 78712 , USA

\begin{abstract}
:
The evolution of Pt nanoparticle cathode electrocatalyst size distribution in a polymer electrolyte membrane fuel cell (PEMFC) was followed during accelerated stress tests using in-operando anomalous small-angle X-ray scattering (ASAXS). This evolution was compared to that observed in an aqueous electrolyte environment using stagnant electrolyte, flowing electrolyte, and flowing electrolyte at elevated temperature to reveal the different degradation trends in the PEMFC and aqueous environments and to determine the relevance of aqueous measurements to
\end{abstract}


the stability of Pt nanoparticle catalyst in the fuel cell environment. The observed changes in the particle size distributions (PSDs) were analyzed to elucidate the extent and mechanisms of particle growth and corresponding mass and active surface area losses in the different environments. These losses indicate a Pt nanoparticle surface area loss mechanism controlled by Pt dissolution, the particle size dependence of Pt dissolution, the loss of dissolved Pt into the membrane and electrolyte, and, to a lesser extent, the re-deposition of dissolved Pt onto larger particles. Based on the geometric surface area loss, mass loss, and mean particle size increase trends, the aqueous environment best reflecting the fuel cell environment was found to be one in which the electrolyte is flowing rather than stagnant. Pt nanoparticle surface area loss resulting from potential cycling can be inhibited by reducing the number of particles smaller than a critical particle diameter (CPD), which was found to be $\sim 3.5$ to $\sim 4 \mathrm{~nm}$, with the CPD dependent on both the cycling protocol (square wave vs triangle wave) and the catalyst environment (fuel cell, aqueous stagnant, aqueous flowing electrolyte, or elevated temperature flowing electrolyte)

Keywords:

Anomalous small-angle X-ray scattering; Catalyst durability; Membrane electrode assembly; Particle size distribution; Platinum Dissolution

\section{Introduction}

Polymer electrolyte membrane fuel cells (PEMFCs) are an attractive energy conversion technology due to their high energy efficiency which results from direct conversion of chemical energy into electrical energy. This technology is currently being developed for both mobile and stationary power applications. Two major issues slowing widespread PEMFC adoption are cost 
and durability. The high cost is greatly influenced by the need for platinum-based electrocatalysts to facilitate the kinetics of the electrode reactions. These catalysts are typically Pt or Pt alloy nanoparticles supported on high surface area carbon. A reduction in power output over time in operating PEMFCs has also been linked to loss of the cathode catalyst electrochemically active surface area (ECA) with load cycling.[1, 2] In this study, the evolution of the Pt cathode electrocatalyst particle size distribution (PSD) in a fuel cell during accelerated stress test (AST) cycling is presented for the first time, providing insight into the degradation mechanisms leading to the loss of fuel cell performance.

Aqueous hydrodynamic techniques, such as thin-film rotating disk electrode measurements, have been used to screen the oxygen reduction reaction (ORR) activity of electrocatalysts prior to incorporation into fuel cells.[3-6] These techniques have also been used to investigate catalyst durability through potential cycling of the catalyst materials either under stagnant electrolyte or hydrodynamic conditions.[7-9] The influence of experimental conditions on the relevance of the aqueous electrolyte durability experiments to the catalyst durability observed in a fuel cell membrane-electrode assembly (MEA) needs to be examined. For example, it has been shown that hydrogen crossover through the ionomer membrane from the anode in the fuel cell environment causes deposition of $\mathrm{Pt}$ in the membrane, effectively acting as a "sink" for Pt dissolving from the cathode catalyst and potentially contributing significantly to cathode catalyst ECA loss.[1] As pointed out by Holby et al.[10, 11], this source of Pt loss from the cathode in the MEA environment is not present in the aqueous environment and may impact the ability of such studies to model the catalyst evolution in the MEA. The goals of this study are to elucidate the degradation mechanisms in both environments using two AST potential cycling protocols, define means to mitigate this degradation, and determine conditions under which the aqueous 
environment mimics the catalyst surface area loss and particle size distribution changes observed in the MEA environment.

Research efforts aimed at exploring the durability and the mechanisms behind the degradation of the platinum-based cathode electrocatalysts for PEM fuel cells have been aided by numerous ex-situ and in-situ spectroscopic and microscopic techniques.[1, 12-24] One of these techniques is small angle X-ray scattering (SAXS) which can be used to determine mean particle size and particle size distributions (PSDs) on the nanometer scale.[25] If scattering patterns are acquired at multiple energies near the absorption edge of the element of interest, a technique termed anomalous SAXS (ASAXS), the PSD of just this element can be resolved.[26, 27] This technique can also yield information about the shape and the total amount of material sampled.

The ASAXS technique at the Pt- $\mathrm{L}_{3}$ absorption edge was used in this study to determine PSDs of nanoparticle Pt electrocatalysts while under potential control in aqueous and MEA environments. The information from this technique is correlated with ECA loss to help understand the mechanisms of ECA loss during potential cycling. This study focuses on the changes in PSDs during potential cycling and on the effects of the environment (i.e., MEA or aqueous), temperature, electrolyte transport, and potential profile on the extent and mechanisms of particle growth and corresponding ECA loss.

\section{Experimental}

\subsection{Preparation of Electrodes}

The catalyst used in this study was prepared by Johnson Matthey Fuel Cells and was comprised of $40 \mathrm{wt} \% \mathrm{Pt}$ nanoparticles supported on an Akzo Nobel Ketjen EC300J (Pt/C) carbon black support. This catalyst was prepared by heat treating the as-prepared catalyst with a $\mathrm{Pt}$ particle mean diameter of $\sim 2 \mathrm{~nm}$ which resulted in a mean Pt particle size of $\sim 3.5 \mathrm{~nm}$, as 
determined through transmission electron microscopy (TEM) analyses by $\mathrm{Yu}$ et al.,[28] and a mean Pt particle size of $\sim 3.2 \mathrm{~nm}$ also determined by TEM by Yang et al.[29] The catalyst is described in detail by Yang et al.[29] A representative TEM image of the catalyst powder and the PSDs derived from TEM images from both Yu et al. and Yang et al. are shown in Fig. 1.[28, 29] The differences in the TEM-derived PSDs illustrate the variation that can occur with limited sampling ( 200 particles by Yu et al. and 80 particles by Yang et al.). Speder et al. have shown limitations of PSD analyses based on TEM alone due to the potential to over- or underestimate particles sizes due to the limited contrast between the nanoparticles and the support.[30] Also included in Fig. 1 is the initial PSD as found in this ASAXS study, showing a mean diameter of $\sim 2.9 \mathrm{~nm}$. The number of particles sampled by ASAXS for the powder catalyst sample was $\sim 10^{13}$.

The working electrodes for the aqueous electrochemical cell were made by depositing an ink of the $40 \mathrm{wt} \% \mathrm{Pt} / \mathrm{C}$ catalyst powder and a water-based perfluorosulfonic acid (PFSA) dispersion on a gas diffusion layer (GDL) consisting of porous carbon paper coated on one side with a microporous layer to form a gas diffusion electrode (GDE) with $0.2 \mathrm{mg} / \mathrm{cm}^{2} \mathrm{Pt}$ loading. The GDEs were subjected to a proprietary procedure to insure wetting of the electrode by the aqueous electrolyte. For the MEA samples, a catalyst-coated membrane (CCM) was made using the Pt/C-PFSA ink described above to prepare a cathode with a loading of $0.22 \mathrm{mg} \mathrm{Pt} / \mathrm{cm}^{2}$. The anode of the CCM contained Pt/C at a loading of $0.32 \mathrm{mg} \mathrm{Pt} / \mathrm{cm}^{2}$. The mean diameter of the anode $\mathrm{Pt} / \mathrm{C}$ was significantly larger $(\sim 12 \mathrm{~nm})$ than that in the cathode in order to differentiate $\mathrm{X}$ ray scatter from the anode and cathode catalysts in the ASAXS data. The membrane was a $25 \mu \mathrm{m}$ thick perfluorosulfonic acid polymer, and the gas diffusion layers were SGL25BC (SGL Group).

\subsection{Aqueous Electrochemical Cell}


Aqueous environment experiments were performed utilizing a PTFE electrochemical cell designed for in-situ X-ray scattering and absorption measurements.[21] A picture of the PTFE electrochemical cell is shown in Fig. S1. The cell has been described previously.[27, 31] For this study, the cell has been modified with an inlet valve fitting on the side and an outlet valve fitting at the top to allow for controlled flow of electrolyte through the cell.

The GDE working electrode was immersed in $\sim 10 \mathrm{~mL}$ of deaerated $0.1 \mathrm{M}$ perchloric acid electrolyte (GFS, double distilled, in $18 \mathrm{M} \Omega$ Millipore water) along with a carbon cloth counter electrode and a micro $\mathrm{Ag} / \mathrm{AgCl}(3 \mathrm{M} \mathrm{KCl}$ filling solution) reference electrode, which was calibrated versus a reversible hydrogen electrode (RHE). All potentials shown are referenced to the RHE scale.

Three aqueous cell potential cycling experiments were performed using a square wave potential profile from 0.4 to $1.05 \mathrm{~V}$ with 10 second holds at each potential. As discussed by Yang et al.[29], this profile was chosen to accelerate Pt degradation as compared to typical potential cycling protocols (e.g., 0.6 to $1.0 \mathrm{~V}, 50 \mathrm{mV} / \mathrm{s}$ triangle profile) and is relevant to fuel cell operation. Potentials higher than the typical hydrogen/air open circuit potential $(1.0 \mathrm{~V})$ can occur during high fuel utilization conditions and/or during startup/shutdown.[32] One experiment in the present work was performed using stagnant room temperature electrolyte. A second used flowing room temperature electrolyte with a volumetric flow rate of $\sim 10 \mathrm{~mL} / \mathrm{min}$. The third used flowing electrolyte heated to a temperature of $80^{\circ} \mathrm{C}$. The final aqueous experiment used $80^{\circ} \mathrm{C}$ flowing electrolyte, but using a triangle potential cycling protocol from 0.6 to $1.0 \mathrm{~V}$ at a scan rate of $50 \mathrm{mV} / \mathrm{s}$, which is the U.S. Department of Energy's accelerated stress test for PEMFC cathode catalyst durability.[33] The cells were cycled for at least 1000 cycles, but with varying total number of cycles (from 1100 to 7500 ) as dictated by ASAXS time constraints. The results 
presented here are for the first 1000 cycles for all the cells. A future article will be devoted to an analysis of ASAXS of these same cells beyond the first 1000 cycles and to a comparison of postmortem TEM and ASAXS results.

\subsection{Membrane Electrode Assembly Cell}

The MEA environment experiment was performed in modified Fuel Cell Technologies, Inc. hardware. This cell has been described previously[34] and was based on a design published by Principi et al.[35] A thin graphite window $(\sim 300 \mu \mathrm{m}$ thick $)$ was milled directly into the anode and cathode graphite cell blocks to allow transmission of incident X-rays to the cathode layer and of X-rays scattered from the cathode layer. Proper operation of the MEA and adequate humidification of the membrane were verified by taking 2 to 4 polarization curves in either $\mathrm{H}_{2} / \mathrm{O}_{2}$ or $\mathrm{H}_{2} /$ air, from 1.00 to $0.35 \mathrm{~V}$. Following this procedure, the potential was cycled following the same square and triangle potential profiles used for the aqueous cell experiments. A summary of the potential cycling parameters for both the MEA and the aqueous experiments is found in Table S1. The MEA was cycled at $80^{\circ} \mathrm{C}$ with an anode gas of $4 \%$ hydrogen (balance argon) and a cathode gas of nitrogen, both at atmospheric pressure and humidified to $100 \%$ relative humidity. A Fuel Cell Technologies, Inc. test stand was used for controlling the temperature, relative humidity, and gas flow rates. A Solartron 1287 potentiostat was used to control the potential and measure the current for both the aqueous and MEA experiments. The ECA of the cathode was measured from a cyclic voltammogram between $0.05 \mathrm{~V}$ and $0.4 \mathrm{~V}$ (vs. RHE) at a sweep rate of $5 \mathrm{mV} / \mathrm{s}$ taken before potential cycling and after every 100 cycles. ECA values were calculated by integrating the hydrogen desorption region and using an area-specific charge of $210 \mu \mathrm{C} / \mathrm{cm}^{2}$. This catalyst had an initial ECA of $\sim 52 \mathrm{~m}^{2} / \mathrm{g}$.[29]

\subsection{Scattering Experiment and Data Analysis}


The ASAXS analyses of the aqueous and MEA cells were performed at the Advanced Photon Source at Argonne National Laboratory at the bending magnet beam line 12-BM. ASAXS scattering patterns were recorded at five different energy levels preceding the Pt- $\mathrm{L}_{3}$ X-ray absorption edge over a scattering vector range of $0.017 \AA^{-1}$ to $0.61 \AA^{-1}$ using a MAR CCD detector. The beam spot size was approximately $0.01 \mathrm{~cm}^{2}$. The ASAXS data analysis utilized Irena, a suite of macros written for the Igor Pro software platform.[36] The Pt scattering data were fit with a lognormal distribution in the Q range of 0.06 to $0.40 \AA^{-1}$ to obtain Pt PSDs of the working electrodes. This $\mathrm{Q}$ range corresponds to a particle size range of $\sim 1.5$ to $10 \mathrm{~nm}$. Previous TEM and XRD studies on carbon-supported Pt nanoparticles, as synthesized and post-mortem, found these distributions are best fit by lognormal functions.[15, 27, 37] The fit assumed the Pt particles to be poly-dispersed spheres, which is the morphology consistent with the TEM images shown in Fig. 1. Large particles that fall outside of the range of the fit (i.e., Pt crystals found in the membrane) are few in number and would have a minimal effect on the PSDs. Geometric surface area (GSA) and mass distributions were also calculated based on the ASAXS-determined number of particles and the assumption of spherical particles. ECA has been shown previously to relate to TEM-determined GSA by a scale factor of less than 1 for mean particle diameters of less than approximately $10 \mathrm{~nm},[28]$ attributed to a portion of the GSA being blocked from reactant access by the carbon support. $[10,28,29,38]$ The scale factor for this catalyst has been previously reported to be 0.8.[38] ASAXS-determined masses were calculated based on a $\mathrm{Pt}$ density of $21.45 \mathrm{~g} / \mathrm{cm}^{3}$.

\subsection{Post-mortem Characterization}

After the cycling experiments, Pt particle sizes were obtained using TEM. Samples were prepared by scraping the cycled catalysts off the GDE and the cathode catalyst layer for the 
MEA and dispersing them in isopropanol to form dilute suspensions. Magnetic stirring at room temperature, followed by an ultrasonic bath were used to form a good dispersion. A small drop of the suspensions was drop-cast onto carbon-lacey copper grids followed by solvent evaporation in air at room temperature. Images were taken using a JEOL 2010F transmission electron microscope at an accelerating voltage of $200 \mathrm{kV}$ at UT-Austin. These images were used to distinguish between individual and agglomerated particles and to estimate the ratio of each type of particle present after cycling.[28] The ImageJ software was used to facilitate this analysis. A comparison of the post-mortem TEM and ASAXS PSDs will be discussed in detail in a future article.

3. Results

\subsection{ASAXS Particle Size Distributions}

The ASAXS-determined Pt PSD changes induced by square wave potential cycling ( 0.4 to $1.05 \mathrm{~V}, 20 \mathrm{~s} /$ cycle) in the aqueous stagnant room temperature (RT), MEA $80^{\circ} \mathrm{C}$, aqueous flowthrough RT, and aqueous flow-through $80^{\circ} \mathrm{C}$ environments are shown in Fig. 2(a-d), respectively. The Pt PSD changes induced by triangle wave potential cycling $(0.6$ to $1.0 \mathrm{~V}$, $50 \mathrm{mV} / \mathrm{s}$ ) in the MEA and aqueous flow-through $80^{\circ} \mathrm{C}$ environments are shown in Fig. 2(e-f). These figures show the initial distributions as well as the PSDs after 100, 200, 500 and 1000 potential cycles.

For all the experiments, the general trend for the evolution of the PSD during cycling up to 1000 cycles is a loss of smaller particles, less than $\sim 3.0 \mathrm{~nm}$, and an increase in the number of particles larger than this diameter. We term the diameter at which there is an overall loss of particles smaller than this diameter and an overall gain in particles larger than this diameter, relative to the initial PSD, the critical particle diameter (CPD). 


\subsection{PSDs analysis and Paper Structure}

The ability of in situ ASAXS to provide the absolute number of particles in the X-ray beam as a function of particle diameter during cycling allows quantification of the loss or gain of particles and their corresponding GSA and mass as a function of particle diameter. The mean diameter increases, the overall loss of GSA, overall mass loss, CPD, mass loss from particles smaller than the CPD, and mass gained in particles larger than the CPD after 1000 cycles will first be presented. The overall Pt loss rates derived from these analyses will then be compared to Pt dissolution rates reported in the literature. The trends in evolution of these parameters with cycling will then be presented. Finally, the particle size dependence of the rates of mass loss/gain after 1000 cycles, the mass change at select particle diameters as a function of cycling, and the changes in number of particles, the mass change, and GSA change for select experiments will be presented. The mechanistic significance of the results will then be discussed in the context of the environment and cycling protocol.

\subsection{Overall Losses after 1000 Cycles}

A summary of the CPD and other key parameters after 1000 potential cycles for all the potential cycling experiments is found in Table 1. The extent of coarsening, shown in Table 1, is defined as the percent of the mass lost from particles smaller than the CPD that is gained back in particles larger than the CPD. These trends are based on the assumption that throughout the cycling the particles are spherical and that the distribution is a continuous lognormal function. Representative TEM images (Fig. 1, initial; Fig. 3, initial and MEA $80^{\circ} \mathrm{C}$ square post-mortem; Fig. S2, post-mortem for all experiments) show that the majority of the particles are spherical in shape and the initial and final distributions (not shown, to be discussed in a future article) resemble a lognormal shape, supporting the use of the lognormal spherical form factor to fit the 
ASAXS data. However, small deviations from these assumptions may lead to uncertainty in the quantitative ASAXS-determined mass and GSA losses. A rapid loss of small particles less than the CPD has been shown in Fig. 2. The rapid loss of small particles leads to the narrowing of the PSD, most evident in the aqueous stagnant RT case (Fig. 2a). An artifact of constraining a narrowed distribution to the lognormal function is a very slight apparent decrease in the number of larger particles. These larger particles have a much larger mass associated with them as compared to smaller particles leading to an overestimation of the total mass loss and, to a lesser degree, the GSA loss. In the most noticeable case of the narrowing, the aqueous stagnant RT experiment, it is estimated that the lognormal constraint caused an error of $\sim 20 \%$ in the overall mass loss (i.e., $6 \%$ loss versus $7 \%$ loss, as shown in Fig. $4 \mathrm{a}$ and an error of $\sim 7 \%$ in the overall GSA loss (i.e., $9 \%$ loss versus $10 \%$ loss).

The general trend in mass loss, GSA loss, mean particle size increase, and change in PSD after 1000 cycles for the different experiments is aqueous flow-through $80^{\circ} \mathrm{C}>$ aqueous flow-through $\mathrm{RT} \approx \mathrm{MEA} 80^{\circ} \mathrm{C}>$ aqueous stagnant $\mathrm{RT}$ and square wave cycling > triangle wave cycling. Similar trends with conditions are observed for the extent of Pt loss smaller than the CPD as were observed for overall loss for the square wave experiments. It is notable that the MEA $80^{\circ} \mathrm{C}$ square and aqueous flow-through RT square cases have almost identical overall loss rates after 1000 cycles, but have different routes for reaching these similar rates: MEA $80^{\circ} \mathrm{C}$ square has both a greater loss of particles with diameters smaller than the CPD and a greater gain of particles larger than the CPD than aqueous flow-through RT square. This greater redistribution of mass is responsible for the larger increase in mean diameter in the MEA experiment.

The mass of $\mathrm{Pt}$ gained in particles larger than the CPD for all elevated temperature experiments is well-correlated $\left(\mathrm{R}^{2}=0.98\right)$ with the mass of Pt lost from particles smaller than the 
CPD. As shown in Table 1, the average extent of coarsening for the elevated temperature experiments is $33 \%$ (i.e., $33 \%$ of mass that is lost from particles smaller than the CPD is gained in particles larger than the CPD and $67 \%$ is lost from the PSD). The two RT experiments, aqueous stagnant RT square and aqueous flow-through RT square, show greater (44\%) and lesser (24\%) extents of coarsening than the $80^{\circ} \mathrm{C}$ experiments, respectively. Elevated temperature was seen to increase both the rate of loss of small particles and the rate of gain of large particles by factors of 1.4 and 2.0, respectively, in the aqueous flow-through environment. The loss rate for the square wave cycling was a factor of 2.2 higher for the MEA environment and a factor of 1.4 higher for the aqueous flow-through $80^{\circ} \mathrm{C}$ environment than that of the triangle wave.

Yang et al.[29] have measured ECA losses for MEAs identical to the ones studied here, with the exception of their use of an anode catalyst with a smaller mean particle size, and Yu et al.[28] have estimated the percentage of initial cathode Pt loading lost from the Yang et al. triangle cycled cells after 10000 cycles using analysis of the post-mortem TEM images of cross-sections of the cell. Yang et al. showed an ECA loss of $31 \%$ after 1000 square cycles and $14 \%$ after 1000 triangle cycles. The GSA losses shown here after 1000 cycles (Table 1) are comparable at $23 \%$ for square and $15 \%$ for triangle. $\mathrm{Yu}$ et al. estimated that $5.9 \%$ of the pre-cycling Pt was precipitated into the membrane after 10000 triangle cycles, corresponding to a Yang et al.measured ECA loss of 48\%, while the overall mass loss from the PSD after 1000 triangle cycles shown here was $7.3 \%$ (Table 1). Surface area losses (GSA or ECA, \%) were observed to be higher than mass losses due to the preferential loss of small particles with the highest specific surface areas $\left(\mathrm{m}^{2} / \mathrm{g}_{\mathrm{Pt}}\right)$ of all particles in the PSD (Fig. 2).

The overall Pt loss rates calculated from the changes in PSD are summarized in Table 2 and are seen to range from $8.2 \times 10^{-11}$ to $2.39 \times 10^{-10} \mathrm{~g}_{\mathrm{Pt}} / \mathrm{cm}^{2}$-cycle. Pt dissolution rates have been 
measured quite extensively for polycrystalline Pt in aqueous environments, [33, 39-49] however there are fewer reported measurements of dissolution rates for carbon-supported nanoparticle $\mathrm{Pt}[38,39,50]$ and none of those report the dissolution rates as a function of temperature or compare them to $\mathrm{Pt}$ loss rates in an MEA. Measured $\mathrm{Pt}$ dissolution rates from $\mathrm{Pt} / \mathrm{C}$ electrocatalysts are only available from aqueous electrolyte experiments, such as those of Sugawara et al.[50] and Kinoshita et al.[39] These measured dissolution rates are shown in Table 2. While direct comparison is not possible due to differences in catalyst type, potential limits, potential scan rates, and electrolyte, the Pt loss rates calculated from the ASAXS experiments on the aqueous systems fall in the range of the measured values reported in the literature.

There are several modeling efforts of Pt electrocatalyst ECA loss in MEAs induced by various potential cycling protocols and temperatures. The Pt dissolution rates utilized in the modeling efforts of Darling and Meyers,[51] Bi et al.,[52] and Zhang et al.[53] are shown in Table 2. The cycling conditions which effect Pt dissolution rates were different in these efforts and differ from what were used in this study, but in general the rates range from $1 \times 10^{-10}$ to $2 \times 10^{-9} \mathrm{~g} / \mathrm{cm}^{2}$-cycle. The dissolution rates calculated from the ASAXS data on the MEAs are $8.7 \times 10^{-11}$ and $1.93 \mathrm{x}$ $10^{-10} \mathrm{~g} / \mathrm{cm}^{2}$-cycle, which are comparable to the modeled literature values.

\subsection{Overall Trends with Potential Cycling}

The evolutions of Pt mass, GSA, and mean diameter over 1000 square wave cycles are shown in Fig. 4 for the aqueous stagnant RT, MEA $80^{\circ} \mathrm{C}$, aqueous flow-through RT, and aqueous flowthrough $80^{\circ} \mathrm{C}$ environments. In general, the mass, GSA, and mean particle size show decreasing rates of change with increasing number of cycles, with the greatest losses of mass and GSA and increase in mean diameter occurring in the first 100 cycles (Fig. S3). For the aqueous stagnant RT case, the majority of mass loss from the PSD (54\%) occurs in the first 100 cycles, whereas all 
other cases show significant rates and the majority of mass loss beyond 100 cycles. The aqueous flow-through RT experiment shows virtually no loss of mass beyond 700 cycles, while aqueous flow-through $80^{\circ} \mathrm{C}$ and $\mathrm{MEA} 80^{\circ} \mathrm{C}$ in general show continuous loss of mass over the entire 1000 cycles.

The GSA loss trends for the four experiments parallel the mass losses to some extent, but significant differences can be noted, such as the similar GSA loss profiles for aqueous flowthrough RT and aqueous flow-through $80^{\circ} \mathrm{C}$, up to 400 cycles, and for aqueous flow-through RT and aqueous flow-through $80^{\circ} \mathrm{C}$, but very different mass loss profiles. While all experiments showed similar GSA losses after 100 cycles, significant differences were observed in the mean diameter increases. These differences relate to the different particle size dependences of Pt loss below the CPD and Pt gain above the CPD, which will be discussed next.

Also included in Fig. $4 \mathrm{~b}$ is the fraction of the initial ECA as a function of the number of cycles for the MEA $80^{\circ} \mathrm{C}$ square cell. The GSA steadily decreased with cycling and resulted in a loss of $23 \%$ after 1000 cycles. The ECA initially increased with a $7 \%$ growth after the first 100 cycles and subsequently decreased with an overall ECA loss of $27 \%$ after 1000 cycles. The simultaneous increase in ECA and decrease in GSA shows that during the first 100 cycles there is an increase in the catalyst utilization (i.e., the catalyst layer is still "conditioning"). In addition, the initial mean diameter of the MEA $80^{\circ} \mathrm{C}$ square cell, which was taken after the conditioning protocol described above, is larger than that of the aqueous samples. These data clearly illustrate that catalyst surface area loss and degradation is occurring during the typical conditioning procedures applied to MEAs.

To further understand the trends in GSA loss, mass loss, and mean diameter increase with cycling, the percent of initial total mass lost due to a decrease in number of particles smaller than 
the CPD and the percent gained through an increase in the number of particles larger than the CPD were analyzed and are shown as a function of number of cycles, along with the total mass loss, in Fig. 5. In all experiments, during all cycle intervals, the majority of Pt that is lost from particles smaller than the CPD is not recaptured in particles larger than the CPD and, in general, the redistribution of mass from particles smaller than the CPD to those larger than the CPD becomes increasingly significant with cycling. As was noted in Fig. 4(b), for the aqueous stagnant RT case, the majority of Pt lost from the PSD occurs during the first 100 cycles (i.e., very little gain in mass above the CPD) and while Pt mass loss from below the CPD continues at approximately a constant rate beyond 100 cycles, gain of mass above the CPD becomes more significant resulting in a primary mechanism of PSD change of redistribution of Pt from below the CPD to above the CPD beyond 100 cycles. In the MEA $80^{\circ} \mathrm{C}$ square case, mass is lost at a constant rate up to 700 cycles, further loss occurs up to 1000 cycles, but at a lower rate, and redistribution of mass from small to large particles occurs at a constant rate from 100 to 600 cycles and slows down beyond 600 cycles. This is also reflected in the lower rate of GSA loss at $>600$ cycles (Fig. 4b). The aqueous flow-through RT case shows a constant rate of Pt loss up to 200 cycles, a much slower rate of loss between 200 and 700 cycles, no loss beyond 700 cycles, and redistribution of mass from small to large particles does not occur, to any significant extent, until 900 and 1000 cycles. The aqueous flow-through $80^{\circ} \mathrm{C}$ case shows characteristics similar to the aqueous stagnant RT square up to 400 cycles, but constant and much higher rates of Pt loss below the CPD from 500 to 1000 cycles, and redistribution of Pt mass from below the CPD to above the CPD occurs at a constant faster rate. The evolutions of the MEA $80^{\circ} \mathrm{C}$ triangle and aqueous flow-through $80^{\circ} \mathrm{C}$ triangle mass losses and gains are very similar to those of their square wave counterparts, albeit at much lower rates. The majority of redistribution of mass 
occurs from 500 to 700 cycles for the aqueous flow-through $80^{\circ} \mathrm{C}$ triangle case and mass loss continues to occur throughout the 1000 cycles.

\subsection{Particle Size Trends with Potential Cycling}

The overall Pt loss and gain trends discussed above and their impact on GSA loss and mean diameter can be understood in the context of the particle size dependence of Pt loss and Pt gain. Fig. 6 shows the number of Pt particles and the mass and GSA of these particles at eight chosen particle diameters $(2.0-5.0 \mathrm{~nm}, \pm 0.02 \mathrm{~nm}$ bins $)$ as a function of number of cycles for the aqueous stagnant, aqueous flow-through RT, and MEA $80^{\circ} \mathrm{C}$ square experiments. In addition to providing insight into the loss mechanisms, these plots provide an interesting perspective on the contribution of the different particle diameters to the overall initial mass and surface area of the catalyst. While the 2.5 and $3.0 \mathrm{~nm}$ particles are present in the highest number in the initial catalyst, the largest contributors to GSA and mass are the 3.0 to $3.5 \mathrm{~nm}$ diameter particles. Particles with diameters outside the 2.5 to $4.0 \mathrm{~nm}$ range contribute relatively small fractions of the initial overall GSA and mass.

As the cells are cycled, loss or gain of particles of particular diameters is observed. The CPD is evident as a plateau region in these plots (e.g., highlighted regions in Fig. 6b). The CPD for the MEA $80^{\circ} \mathrm{C}$ square cell initially starts at $\sim 3 \mathrm{~nm}$ over the first 100 cycles. It then transitions to $\sim 3.25 \mathrm{~nm}$ from cycle 100 to 500 and to $\sim 3.5$ from cycle 500 to 1000 . Fig. 6 also clearly illustrates that Pt loss rates for particles with diameters less than the critical diameter are inversely dependent on particle size by comparing, for example, the initial slopes of the $2.0 \mathrm{~nm}$ and $2.5 \mathrm{~nm}$ lines. Particles with diameters of $\geq 4.0 \mathrm{~nm}$ are stable against loss over the 1000 square wave cycles. 
For the aqueous stagnant RT case, the majority of Pt lost from the PSD that occurs during the first 100 cycles can be attributed to loss of particles smaller than $\sim 3 \mathrm{~nm}$. This loss comprises the majority (54\%) of the overall mass loss for the 1000 cycles and a significant percentage of the GSA loss (33\%). There is a minor contribution to mass loss from the apparent loss of particles $>4.0 \mathrm{~nm}$ due to the constraints of the lognormal fitting discussed above. The rate of loss of particles smaller than $\sim 3 \mathrm{~nm}$ begins to slow dramatically after 400 cycles even though a large fraction of these small particles remain even up to 1000 cycles, indicating that depletion of these particles is not the driving force for the reduction in the loss rate. The mass of particles of $\sim 3 \mathrm{~nm}$ is very stable in this system and the loss rate of particles smaller than $\sim 3 \mathrm{~nm}$ is slower in this cell compared to all other cells, thus the mass and surface area losses are also relatively minor.

The MEA $80^{\circ} \mathrm{C}$ square case shows loss of almost all of the $\sim 2 \mathrm{~nm}$ particles and loss of $\sim 60 \%$ of the $\sim 2.5 \mathrm{~nm}$ particles over just 600 cycles. The lower overall mass loss rate beyond 700 cycles and the lower rates of mass redistribution from small to large particles, noted earlier, results from depletion of the particles smaller than $\sim 2.5 \mathrm{~nm}$. Unlike the aqueous stagnant RT case, particles in the 3 to $3.25 \mathrm{~nm}$ diameter range, which are the largest contributors to the initial GSA, show significant loss over the 1000 cycles resulting in the much higher GSA loss for this sample.

The aqueous flow-through RT square experiment, which most closely mimics the overall mass and GSA losses observed in the MEA $80^{\circ} \mathrm{C}$ square experiment, showed slightly lower rates of loss of particles smaller than $\sim 3 \mathrm{~nm}$, unlike the MEA, and no increase in mass or GSA increase for particles larger than $\sim 3 \mathrm{~nm}$ until 900 cycles. As noted earlier, this lack of redistribution of mass from particles smaller than $\sim 3 \mathrm{~nm}$ to larger particles up to 900 cycles results in a lower increase in mean diameter. 
The trends in mass loss as a function of particle size and number of cycles are more easily discernible in plots of $\mathrm{Pt}$ loss rates for a given particle size $( \pm 0.02 \mathrm{~nm})$ normalized to the initial GSA of this particle size range after 1000 cycles and after select number of cycles. These plots are shown for all six experiments in Fig. 7 and Fig. 8, respectively. Rates greater than zero indicate a loss of $\mathrm{Pt}$ from the given particle size and rates less than zero indicate a gain of $\mathrm{Pt}$ to the given particle size. The CPD for each of these experiments, which were tabulated in Table 1 for 1000 cycles, is clearly evident in these plots as the diameter where the Pt loss rates transition from positive to negative values. Fig. 7 shows that all experiments have similar trends in the particle size dependence of Pt loss rate, with the exception of MEA $80^{\circ} \mathrm{C}$ square and aqueous stagnant RT square, which show greater dependencies of Pt loss rate on particle size. Fig. 8 clearly illustrates that the CPD increases with number of cycles for all conditions except the aqueous stagnant RT. In general the Pt loss rates were found to decrease with cycling for particle sizes less than the CPD, which was illustrated in Fig. 6 for three representative experiments to be due to a significant decrease in the number of particles smaller, in general, than $\sim 3 \mathrm{~nm}$. The rate of increase in the mass of particles larger than the CPD in general decreases with cycling for all cases except aqueous stagnant RT, where the rate is nearly constant with cycling. The combined effects of a decrease in the loss rate of particles smaller than the CPD due to a diminishing number of these particles, a decrease in gain rate for particles larger than the CPD, and an increase in the CPD with cycling result in a transition from fast loss and gain toward slower more even overall rates of Pt loss over the entire particle size range with cycling.

\section{Discussion}

The results of this study are consistent with a Pt nanoparticle surface area loss mechanism controlled by Pt dissolution, the particle size dependence of Pt dissolution, the loss of dissolved 
Pt into the ionomer, membrane, and electrolyte, and, to a lesser extent, the re-deposition of dissolved Pt onto larger particles. The mechanism that has been proposed previously to explain surface area loss in the aqueous environment is preferential dissolution of small particles with a secondary particle growth mechanism of re-deposition (coarsening) of the dissolved Pt species onto existing particles.[10, 11, 20, 27] A particle size dependence of Pt loss rates was observed in this study (Fig. 6, Fig. 7, Fig. 8), which is consistent with a loss mechanism controlled by dissolution. The particle size dependence of Pt dissolution has been attributed to the GibbsThomson effect which induces an effectively higher potential on smaller particles as compared to larger ones and a Pt dissolution equilibrium and rate which increase with increasing anodic potential above $\sim 0.7$ V.[10, 11, 20, 28, 38].

As described by Zhang et al., the ultimate disposition of Pt dissolving from small particles in the PSD depends on the state of the surface of the Pt particles after the Pt dissolves and the driving forces for re-deposition of the dissolved Pt, which are the effective potential on the nanoparticles and the concentration of dissolved $\mathrm{Pt}$ in the ionomer and electrolyte surrounding the nanoparticles.[53] The concentration of dissolved Pt is controlled by the competing rates of Pt dissolution and diffusion of dissolved Pt from the electrode layer. The upper potential limit, the anodic scan rate, and the duration of the dwell at the upper potential limit define the extent of Pt dissolution during the anodic portion of a cycle.[27, 54] Re-deposition will occur when metallic sites are present on the particle surfaces[53] and when the concentration of dissolved Pt surrounding the particles is higher than the equilibrium dissolved Pt concentration, which is a function of Pt particle size.[55]

The extent of GSA loss for the experiments in this study can be interpreted in the context of the proposed mechanism. In the aqueous stagnant RT case, the smallest Pt particles in the initial 
PSD, which have the highest equilibrium dissolved Pt concentrations and the fastest dissolution rates,[20, 28, 51, 55] are dissolved into the ionomer and electrolyte surrounding the particles. Since the electrolyte is stagnant, there is no transport of dissolved Pt out of the system and the concentration of dissolved Pt increases with cycling. Pt dissolution stops and deposition occurs when the dissolved concentration in the electrolyte becomes higher than the equilibrium dissolved potential for a given particle diameter. The equilibrium dissolved concentration is inversely proportional to particle size, $[20,55]$ thus the dissolution of small particles decreases with increasing number of cycles and dissolved Pt preferentially deposits on the larger particles in the distribution. The increase in the extent of coarsening with cycling in the aqueous stagnant RT environment, as shown in Fig. 5a, indicates that re-deposition of Pt onto larger particles or coalescence becomes more of a significant factor in the growth mechanism with continued cycling. The TEM results of this study indicate that coalesced particles represent a very minor fraction of the overall particles imaged $(<2 \%)$ and thus the re-deposition interpretation is favored and re-deposition is not causing coalescence to any significant extent.[28, 55] The TEM data showing the majority of particles remain spherical after cycling also indicates that the redeposition process onto larger particles is isotropic. This mechanistic transition from predominantly Pt loss to loss followed by re-deposition with cycling can potentially explain the "plateau" region in the mean diameter growth trend observed in several studies.[21, 24, 26, 27]

In the flowing electrolyte experiments, small particles initially dissolve at the same rate as that observed in the aqueous stagnant system. However, unlike the stagnant case, dissolved Pt that diffuses through the ionomer and into the electrolyte is transported out of the system. Redeposition occurs both during the anodic hold while metallic sites still exist on the Pt particle surfaces[53] and during the cathodic portion of the cycle profile. The observation of significant 
deposition in the flowing electrolyte system $\left(33 \%\right.$ of dissolved $\mathrm{Pt}$ is re-deposited for the $80^{\circ} \mathrm{C}$ flow-through experiments) indicates that the re-deposition rate of $\mathrm{Pt}$ is sufficiently fast, compared to the rate at which dissolved Pt is transported out of the ionomer and through a boundary layer of stagnant/slower flowing electrolyte surrounding the GDE, to initiate reprecipitation. An effective $\mathrm{Pt}^{2+}$ diffusion coefficient at $80^{\circ} \mathrm{C}$ of $3.4 \times 10^{-6} \mathrm{~cm}^{2} / \mathrm{s}$ from Holby et al. $[10,11]$ and a $10 \mathrm{~s}$ hold at the anodic potential yields a $\mathrm{Pt}^{2+}$ diffusion length of $\sim 58 \mu \mathrm{m}$ during one cycle. This order of magnitude boundary layer thickness is commensurate with the low flow and geometry of the system. The future article will elaborate on the boundary layer thickness in this system. The extent of coarsening for aqueous flow-through RT (24\%, Table 1) was lower than that observed for all the elevated temperature experiments (average: 33\%), implying that the re-deposition rate is less dependent on temperature than the dissolution rate.

Unlike the stagnant system, the transport of dissolved Pt out of the system by the flowing electrolyte, which serves to maintain the dissolved Pt concentration lower than the equilibrium concentration for the particles smaller than the CPD in the PSD, drives the continuing loss of particles throughout the 1000 cycles. The increase in CPD with cycling is due to depletion of smaller particles. The greater loss of GSA in the case of flowing electrolyte shown here agrees with the RDE results of Nagai et al. showing that ECA loss increases with increasing rotation rate, which they attributed to increased $\mathrm{Pt}$ dissolution and decreased re-deposition due to increased rates of transport of dissolved Pt from the RDE tip.[56]

Unlike the aqueous environment, the MEA environment has a smaller volume of electrolyte than the aqueous stagnant and a much smaller volume than the aqueous flowing experiment. In this case, there is no "reservoir" for dissolved Pt. However, a factor present in the MEA environment that is not present in the aqueous environment is hydrogen which diffuses from the 
anode to cathode through the membrane (i.e., termed "hydrogen crossover"). The theoretical work of Holby et al. explored the impact of hydrogen crossover on the catalyst degradation.[10] It was shown that crossover hydrogen causes a greater loss of surface area, hinders coarsening of larger particles within the size distribution, and that the growth of the mean diameter over time is suppressed (Holby et al.; Fig. 4)[10]. The relative comparison between the MEA and aqueous environment results from this study show correlation with the theoretically-calculated results when hydrogen crossover is and is not included in the model. The aqueous stagnant results can be thought of as being similar to the model where there is no hydrogen crossover. As with the greater loss of surface area due to hydrogen crossover in the theoretical work, there is also a similar greater loss of GSA in the MEA environment as compared to the aqueous stagnant environment (Fig. 4). However, unlike the model results from Holby et al. there was greater growth in the mean diameter in the MEA environment ( $0.44 \mathrm{~nm}$ after 1000 cycles) than in the aqueous stagnant environment $(0.18 \mathrm{~nm})$. This greater growth is mainly attributed to greater loss of small Pt particles in the MEA environment than in the aqueous stagnant environment. The absence of this growth in the predictions of Holby et al. may be attributed to their use, in their hydrogen crossover effect analysis, of constant potential rather than potential cycling conditions. Constant potential holds have been shown to result in lower Pt dissolution rates. $[39,40,50]$ However, the loss of small particles playing a dominant role in the average size change is consistent with the additional potential cycling simulations performed by Holby et al.[10]

Triangle wave cycling was observed to cause lower GSA loss and mean particle increase as compared to square wave cycling in the same environment. These results agree with those of Yang et al. who showed that square wave cycling caused greater loss of ECA and mean particle increase versus triangle wave cycling for the same catalyst used in this study in an MEA 
containing this catalyst.[29] This phenomenon has been correlated with the higher oxide coverages which occur during the square wave profile [27] and with the associated greater Pt dissolution rates[57, 58] that occurs due to the work done during the oxide formation and stripping.[11]

\section{Conclusions}

The goals of this work were to determine which environment best mimicked the MEA environment in terms of catalyst degradation, loss of surface area and growth in mean diameter, and to determine the mechanisms of catalyst degradation in the various environments. The overall trends in GSA loss for the different experimental environments after 1000 potential cycles is aqueous flow-through $80^{\circ} \mathrm{C}>$ aqueous flow-through $\mathrm{RT} \approx \mathrm{MEA} 80^{\circ} \mathrm{C}>>$ aqueous stagnant RT and square wave cycling $>$ triangle wave cycling. These trends are well-correlated with the overall loss of Pt from the PSDs.

The changes in the PSDs, the GSAs, and the mean diameters during cycling were determined to be controlled by the cycling dependence of the loss rates of particles smaller than the CPD, the cycling dependence of the rate of gain of larger particles, and the relative rates of the two processes, which defines what fraction of Pt is completely lost from the PSD. The loss rates were found to be greater than the gain rates in all cases leading to the loss of particles smaller than the CPD being the major contributor to GSA loss and mean particle size increase.

For all elevated temperature experiments, the percent of Pt lost that was recaptured in the large particle regime was on average $33 \%$. The gain or recapture rate was found to be more dependent on temperature than the loss rate. Room temperature rather than elevated temperatures increased the percent of Pt that is lost from the PSD and not retained to $76 \%$. Elevated 
temperature was seen to increase both the rate of loss of small particles and the rate of gain of large particles by factors of 1.4 and 2.0 , respectively.

The results of this study are consistent with a Pt nanoparticle surface area loss mechanism controlled by Pt dissolution, the particle size dependence of Pt dissolution, the loss of dissolved Pt into the membrane and electrolyte, and, to a lesser extent, the re-deposition of dissolved Pt onto larger particles. With stagnant electrolyte, where dissolved Pt is not transported out of the system, the degradation mechanism is dominated by dissolution of smaller particles in the initial stages of cycling followed by a mechanism more evenly distributed between dissolution of Pt from the smaller particles and re-precipitation of the dissolved species onto larger existing particles. In the MEA environment and with the flowing electrolyte case, dissolution is observed up to larger particle diameters than with stagnant electrolyte. This is due to transport of dissolved Pt from the system, driven by a dissolved Pt concentration gradient between the electrode and membrane established by deposition of dissolved Pt in the membrane which acts as a "sink" for dissolved $\mathrm{Pt}$ and by removal of dissolved $\mathrm{Pt}$ by the flowing electrolyte. Re-deposition of dissolved Pt onto existing particles is suppressed in these cases compared to the stagnant electrolyte case. TEM results indicate that re-deposition induced coalescence was a minor contributor to the overall losses in these experiments.

The results of this study show that the aqueous environment best reflecting the MEA environment in terms of GSA loss, mass loss, and mean particle increase is one in which the electrolyte is flowing rather than stagnant. This result is consistent with the idea that the Pt nanoparticle evolution in the MEA is significantly influenced by loss of dissolved Pt to the Pt "sink", $[10,11,51]$ an effect which is mimicked by the flowing electrolyte. Elevating the temperature of the flowing electrolyte to match the temperature of the MEA caused greater 
degradation than observed in the MEA and thus may be useful for accelerated stress testing of catalyst durability. This result also suggests that RDE potential cycling experiments to determine catalyst durability should be performed while rotating the RDE and not under stagnant conditions.

Triangle wave cycling was observed to cause lower GSA loss and mean particle size increase as compared to square wave cycling in the same environment, consistent with earlier studies of showing greater loss of ECA and mean particle increase for the square wave cycling.[29]

Pt loss rates calculated from the changes in PSDs ranged from $8.2 \times 10^{-11}$ (aqueous stagnant RT square) to $2.39 \times 10^{-10} \mathrm{~g} / \mathrm{cm}^{2}$-cycle (aqueous flow-through $80^{\circ} \mathrm{C}$ square), and were found to be comparable to measured values reported in the literature for aqueous environments and to values derived from literature modeling efforts. The results of this study show that catalyst surface area loss and the associated PEMFC performance loss observed with load cycling can be minimized by decreasing the fraction of particles with diameters smaller than the CPD observed here ( $\sim 3.5$ to $\sim 4 \mathrm{~nm}$ ), which would result in less Pt dissolution and loss.

\section{Acknowledgements}

The authors would like to thank Sarah Ball, Jonathan Sharman, Brian Theobald, and Graham Hards from Johnson Matthey Technology Centre for the catalyst and catalyst-coated membrane fabrication and for their supportive discussions. We would also like to thank the staff of Sector 12 at Advanced Photon Source, especially Soenke Seifert and Sungsik Lee, for their knowledge and assistance during the ASAXS experiments. We would also like to thank Jan Ilavsky for his expertise and many helpful discussions regarding the ASAXS data analysis. Electron microscopy was performed at University of Texas-Austin. We would like to thank Andres Godoy for his 
help with the TEM sample preparation. Finally, we thank the Department of Energy, Office of Energy Efficiency and Renewable Energy, Fuel Cell Technologies Program (Nancy Garland, DOE Program Manager), for funding this work, and the U.S. Department of Energy, Office of Basic Energy Sciences for support of the Advanced Photon Source. Argonne is a U.S. Department of Energy Office of Science Laboratory operated under Contract No. DE-AC0206CH11357 by UChicago Argonne, LLC.

\section{References}

[1] P. Ferreira, G. la O', Y. Shao-Horn, D. Morgan, R. Makharia, S. Kocha, H. Gasteiger, Instability of $\mathrm{Pt} / \mathrm{C}$ electrocatalysts in proton exchange membrane fuel cells - A mechanistic investigation, Journal of the Electrochemical Society, 152 (2005) A2256-A2271.

[2] F.A. de Bruijn, V.A.T. Dam, G.J.M. Janssen, Durability and degradation issues of PEM fuel cell components, Fuel Cells, 8 (2008) 3-22.

[3] H.A. Gasteiger, S.S. Kocha, B. Sompalli, F.T. Wagner, Activity benchmarks and requirements for Pt, Pt-alloy, and non-Pt oxygen reduction catalysts for PEMFCs, Applied Catalysis B-Environmental, 56 (2005) 9-35.

[4] U.A. Paulus, T.J. Schmidt, H.A. Gasteiger, R.J. Behm, Oxygen reduction on a high-surface area Pt/Vulcan carbon catalyst: a thin-film rotating ring-disk electrode study, J. Electroanal. Chem., 495 (2001) 134-145.

[5] K.J.J. Mayrhofer, D. Strmcnik, B.B. Blizanac, V. Stamenkovic, M. Arenz, N.M. Markovic, Measurement of oxygen reduction activities via the rotating disc electrode method: From Pt model surfaces to carbon-supported high surface area catalysts, Electrochim. Acta, 53 (2008) 3181-3188.

[6] E. Higuchi, H. Uchida, M. Watanabe, Effect of loading level in platinum-dispersed carbon black electrocatalysts on oxygen reduction activity evaluated by rotating disk electrode, J. Electroanal. Chem., 583 (2005) 69-76.

[7] I. Takahashi, S.S. Kocha, Examination of the activity and durability of PEMFC catalysts in liquid electrolytes, Journal of Power Sources, 195 (2010) 6312-6322.

[8] W.C. Sheng, S. Chen, E. Vescovo, Y. Shao-Horn, Size Influence on the Oxygen Reduction Reaction Activity and Instability of Supported Pt Nanoparticles, Journal of the Electrochemical Society, 159 (2012) B96-B103.

[9] C. Wang, D. van der Vliet, K.L. More, N.J. Zaluzec, S. Peng, S.H. Sun, H. Daimon, G.F. Wang, J. Greeley, J. Pearson, A.P. Paulikas, G. Karapetrov, D. Strmcnik, N.M. Markovic, V.R. Stamenkovic, Multimetallic Au/FePt3 Nanoparticles as Highly Durable Electrocatalyst, Nano Letters, 11 (2011) 919-926.

[10] E.F. Holby, W.C. Sheng, Y. Shao-Horn, D. Morgan, Pt nanoparticle stability in PEM fuel cells: influence of particle size distribution and crossover hydrogen, Energy Environ. Sci., 2 (2009) 865-871. 
[11] E.F. Holby, D. Morgan, Application of Pt Nanoparticle Dissolution and Oxidation Modeling to Understanding Degradation in PEM Fuel Cells, Journal of the Electrochemical Society, 159 (2012) B578-B591.

[12] J. Xie, D.L. Wood, K.L. More, P. Atanassov, R.L. Borup, Microstructural changes of membrane electrode assemblies during PEFC durability testing at high humidity conditions, Journal of the Electrochemical Society, 152 (2005) A1011-A1020.

[13] J. Xie, D.L. Wood, D.M. Wayne, T.A. Zawodzinski, P. Atanassov, R.L. Borup, Durability of PEFCs at high humidity conditions, Journal of the Electrochemical Society, 152 (2005) A104A113.

[14] K. Yasuda, A. Taniguchi, T. Akita, T. Ioroi, Z. Siroma, Platinum dissolution and deposition in the polymer electrolyte membrane of a PEM fuel cell as studied by potential cycling, Phys. Chem. Chem. Phys., 8 (2006) 746-752.

[15] R.L. Borup, J.R. Davey, F.H. Garzon, D.L. Wood, M.A. Inbody, PEM fuel cell electrocatalyst durability measurements, Journal of Power Sources, 163 (2006) 76-81.

[16] S.J.C. Cleghorn, D.K. Mayfield, D.A. Moore, J.C. Moore, G. Rusch, T.W. Sherman, N.T. Sisofo, U. Beuscher, A polymer electrolyte fuel cell life test: 3 years of continuous operation, Journal of Power Sources, 158 (2006) 446-454.

[17] M. Schulze, A. Schneider, E. Gulzow, Alteration of the distribution of the platinum catalyst in membrane-electrode assemblies during PEFC operation, Journal of Power Sources, 127 (2004) 213-221.

[18] Y. Shi, A. Horky, O. Polevaya, J. Cross, Correlations Between Durability and Degradation Mechanisms for PEMFC by in situ and Post Mortem Analysis, Fuel Cell SeminarPalm Springs, CA, 2005.

[19] R. Borup, J. Meyers, B. Pivovar, Y. Kim, R. Mukundan, N. Garland, D. Myers, M. Wilson, F. Garzon, D. Wood, P. Zelenay, K. More, K. Stroh, T. Zawodzinski, J. Boncella, J. McGrath, M. Inaba, K. Miyatake, M. Hori, K. Ota, Z. Ogumi, S. Miyata, A. Nishikata, Z. Siroma, Y. Uchimoto, K. Yasuda, K. Kimijima, N. Iwashita, Scientific aspects of polymer electrolyte fuel cell durability and degradation, Chemical Reviews, (2007) 3904-3951.

[20] Y. Shao-Horn, W. Sheng, S. Chen, P. Ferreira, E. Holby, D. Morgan, Instability of supported platinum nanoparticles in low-temperature fuel cells, Topics in Catalysis, (2007) 285305.

[21] M.C. Smith, J.A. Gilbert, J.R. Mawdsley, S. Seifert, D.J. Myers, In situ small-angle X-ray scattering observation of Pt catalyst particle. growth during potential cycling, Journal of the American Chemical Society, 130 (2008) 8112-8113.

[22] H.G. Haubold, X.H. Wang, G. Goerigk, W. Schilling, In situ anomalous small-angle X-ray scattering investigation of carbon-supported electrocatalysts, Journal of Applied Crystallography, 30 (1997) 653-658.

[23] H.G. Haubold, X.H. Wang, H. Jungbluth, G. Goerigk, W. Schilling, In situ anomalous small-angle X-ray scattering and X-ray absorption near-edge structure investigation of catalyst structures and reactions, Journal of Molecular Structure, 383 (1996) 283-289.

[24] C. Yu, E.F. Holby, R. Yang, M.F. Toney, D. Morgan, P. Strasser, Growth Trajectories and Coarsening Mechanisms of Metal Nanoparticle Electrocatalysts, Chemcatchem, 4 (2012) 766770.

[25] T. Narayanan, Soft Matter: Scattering, Imaging, and Manipulation, 1st ed., Springer, Berlin, 2007. 
[26] C.F. Yu, S. Koh, J.E. Leisch, M.F. Toney, P. Strasser, Size and composition distribution dynamics of alloy nanoparticle electrocatalysts probed by anomalous small angle X-ray scattering (ASAXS), Faraday Discuss., 140 (2008) 283-296.

[27] J.A. Gilbert, N.N. Kariuki, R. Subbaraman, A.J. Kropf, M.C. Smith, E.F. Holby, D. Morgan, D.J. Myers, In Situ Anomalous Small-Angle X-ray Scattering Studies of Platinum Nanoparticle Fuel Cell Electrocatalyst Degradation, Journal of the American Chemical Society, 134 (2012) 14823-14833.

[28] K. Yu, D.J. Groom, X.P. Wang, Z.W. Yang, M. Gummalla, S.C. Ball, D.J. Myers, P.J. Ferreira, Degradation Mechanisms of Platinum Nanoparticle Catalysts in Proton Exchange Membrane Fuel Cells: The Role of Particle Size, Chemistry of Materials, 26 (2014) 5540-5548. [29] Z. Yang, S. Ball, D. Condit, M. Gummalla, Systematic Study on the Impact of Pt Particle Size and Operating Conditions on PEMFC Cathode Catalyst Durability, Journal of the Electrochemical Society, 158 (2011) B1439-B1445.

[30] J. Speder, L. Altmann, M. Roefzaad, M. Baumer, J.J.K. Kirkensgaard, K. Mortensen, M. Arenz, Pt based PEMFC catalysts prepared from colloidal particle suspensions - a toolbox for model studies, Phys. Chem. Chem. Phys., 15 (2013) 3602-3608.

[31] D. Myers, J. Gilbert, X. Wang, N. Kariuki, S. Niyogi, A.J. Kropf, D. Morgan, S. Ball, J. Sharman, B. Theobald, G. Hards, American Chemical Society, Division of Fuels Chemistry, 57 (2012) 414.

[32] C.A. Reiser, L. Bregoli, T.W. Patterson, J.S. Yi, J.D.L. Yang, M.L. Perry, T.D. Jarvi, A reverse-current decay mechanism for fuel cells, Electrochem. Solid State Lett., 8 (2005) A273A276.

[33] R. Borup, J. Meyers, B. Pivovar, Y.S. Kim, R. Mukundan, N. Garland, D. Myers, M. Wilson, F. Garzon, D. Wood, P. Zelenay, K. More, K. Stroh, T. Zawodzinski, J. Boncella, J.E. McGrath, M. Inaba, K. Miyatake, M. Hori, K. Ota, Z. Ogumi, S. Miyata, A. Nishikata, Z. Siroma, Y. Uchimoto, K. Yasuda, K.-i. Kimijima, N. Iwashita, Scientific aspects of polymer electrolyte fuel cell durability and degradation, Chemical Reviews, 107 (2007) 3904-3951.

[34] D. Myers, X. Wang, N. Kariuki, S. Niyogi, J. Mawdsley, J.D. Carter, Non-Platinum Bimetallic Cathode Electrocatalysts, FY 2010 DOE Hydrogen Program Annual Progress Report, U.S. Department of Energy, 2010, pp. 811.

[35] E. Principi, A. Di Cicco, A. Witkowska, R. Marassi, Performance of a fuel cell optimized for in situ X-ray absorption experiments, J. Synchrot. Radiat., 14 (2007) 276-281.

[36] J. Ilavsky, P.R. Jemian, Irena: tool suite for modeling and analysis of small-angle scattering, Journal of Applied Crystallography, 42 (2009) 347-353.

[37] H. Borchert, E.V. Shevehenko, A. Robert, I. Mekis, A. Kornowski, G. Grubel, H. Weller, Determination of nanocrystal sizes: A comparison of TEM, SAXS, and XRD studies of highly monodisperse COPt3 particles, Langmuir, 21 (2005) 1931-1936.

[38] R.K. Ahluwalia, S. Arisetty, J.-K. Peng, R. Subbaraman, X. Wang, N. Kariuki, D.J. Myers, R. Mukundan, R. Borup, O. Polevaya, Dynamics of Particle Growth and Electrochemical Surface AreaLoss due to Platinum Dissolution, Journal of The Electrochemical Society, 161 (2014) F291-F304.

[39] K. Kinoshita, J.T. Lundquist, P. Stonehart, Potential cycling effects on platinum electrocatalyst surfaces, Journal of Electroanalytical Chemistry and Interfacial Electrochemistry, 48 (1973) 157-166. 

Electrodes in 1 M Sulfuric-Acid by Cyclic Voltammetry, J. Electroanal. Chem., 35 (1972) 209$\&$.

[41] D.C. Johnson, D.T. Napp, S.A. Bruckenstein, A ring-disk electrode study of the current/potential behaviour of platinum in $1.0 \mathrm{M}$ sulphuric and $0.1 \mathrm{M}$ perchloric acids, Electrochim. Acta, 15 (1970) 1493-1509.

[42] X.P. Wang, R. Kumar, D.J. Myers, Effect of voltage on platinum dissolution relevance to polymer electrolyte fuel cells, Electrochem. Solid State Lett., 9 (2006) A225-A227.

[43] M. Umeda, Y. Kuwahara, A. Nakazawa, M. Inoue, Pt Degradation Mechanism in Concentrated Sulfuric Acid Studied Using Rotating Ring-Disk Electrode and Electrochemical Quartz Crystal Microbalance, J Phys Chem C, 113 (2009) 15707-15713.

[44] S. Takizawa, A. Nakazawa, M. Inoue, M. Umeda, Anodic Pt dissolution in concentrated trifluoromethanesulfonic acid, Journal of Power Sources, 195 (2010) 5966-5970.

[45] V. Komanicky, K.C. Chang, A. Menzel, N.M. Markovic, H. You, X. Wang, D. Myers, Stability and dissolution of platinum surfaces in perchloric acid, Journal of the Electrochemical Society, 153 (2006) B446-B451.

[46] S. Mitsushima, Y. Koizumi, S. Uzuka, K.I. Ota, Dissolution of platinum in acidic media, Electrochim. Acta, 54 (2008) 455-460.

[47] V.A.T. Dam, F.A. de Bruijn, The stability of PEMFC electrodes - Platinum dissolution vs potential and temperature investigated by quartz crystal microbalance, Journal of the Electrochemical Society, 154 (2007) B494-B499.

[48] S. Cherevko, A.A. Topalov, A.R. Zeradjanin, G.P. Keeley, K.J.J. Mayrhofer, TemperatureDependent Dissolution of Polycrystalline Platinum in Sulfuric Acid Electrolyte, ElectrocatalysisUs, 5 (2014) 235-240.

[49] P. Bindra, S.J. Clouser, E. Yeager, Platinum Dissolution in Concentrated Phosphoric-Acid, Journal of the Electrochemical Society, 126 (1979) 1631-1632.

[50] Y. Sugawara, T. Okayasu, A.P. Yadav, A. Nishikata, T. Tsuru, Dissolution Mechanism of Platinum in Sulfuric Acid Solution, Journal of the Electrochemical Society, 159 (2012) F779F786.

[51] R.M. Darling, J.P. Meyers, Kinetic model of platinum dissolution in PEMFCs, Journal of the Electrochemical Society, 150 (2003) A1523-A1527.

[52] W. Bi, T.F. Fuller, Modeling of PEM fuel cell Pt/C catalyst degradation, Journal of Power Sources, 178 (2008) 188-196.

[53] H. Zhang, H. Haas, J.W. Hu, S. Kundu, M. Davis, C. Chuy, The Impact of Potential Cycling on PEMFC Durability, Journal of the Electrochemical Society, 160 (2013) F840-F847.

[54] M. Uchimura, S. Kocha, The Impact of Cycle Profile on PEMFC Durability, ECS Transactions, 11 (2007) 1215-1226.

[55] R.K. Ahluwalia, S. Arisetty, X.P. Wang, X.H. Wang, R. Subbaraman, S.C. Ball, S. DeCrane, D.J. Myers, Thermodynamics and Kinetics of Platinum Dissolution from CarbonSupported Electrocatalysts in Aqueous Media under Potentiostatic and Potentiodynamic Conditions, Journal of the Electrochemical Society, 160 (2013) F447-F455.

[56] T. Nagai, H. Murata, Y. Morimoto, The Influence of Experimental Conditions on the Catalyst Degradation in the Accelerated Durability Test using a Rotating Disk Electrode, ECS Transactions, 50 (2013) 1539-1546.

[57] M. Uchimura, S. Sugawara, Y. Suzuki, J. Zhang, S.S. Kocha, Electrocatalyst Durability under Simulated Automotive Drive Cycles, ECS Transactions, 16 (2008) 225-234. 
[58] C.H. Paik, G.S. Saloka, G.W. Graham, Influence of cyclic operation on PEM fuel cell catalyst stability, Electrochem. Solid State Lett., 10 (2007) B39-B42. 
1

2

3

4

5

6

7

8

9

10

11

12

13

14

15

16

17

18

19

20

21

22

23

24

25

26

27

28

29

30

31

32

33

34

35

36

37

38

39

40

41

42

43

44

45

46

47

48

49

50

51

52

53

54

55

56

57

58

59

60

61

62

63

64

65

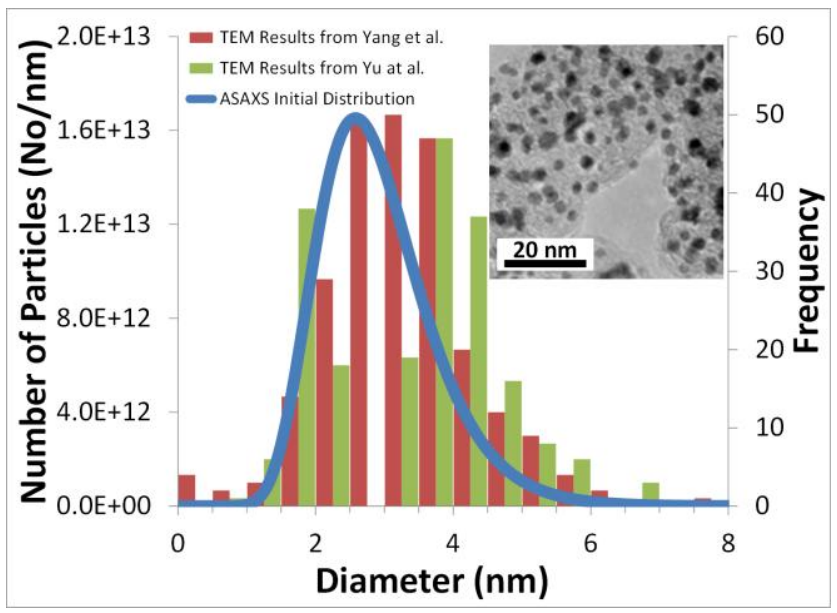

Fig. 1. Particle size distributions of heat treated $40 \mathrm{wt} \% \mathrm{Pt} / \mathrm{Ketjen} \mathrm{EC} 300 \mathrm{~J}$ catalyst as found through ASAXS (blue line) and TEM (Yu et al. (green bars) and Yang et al. (red bars)). Inset: Representative TEM image of $40 \mathrm{wt} \% \mathrm{Pt} / \mathrm{Ketjen}$ EC 300J. 
Square Wave $(0.4-1.05 \mathrm{~V})$
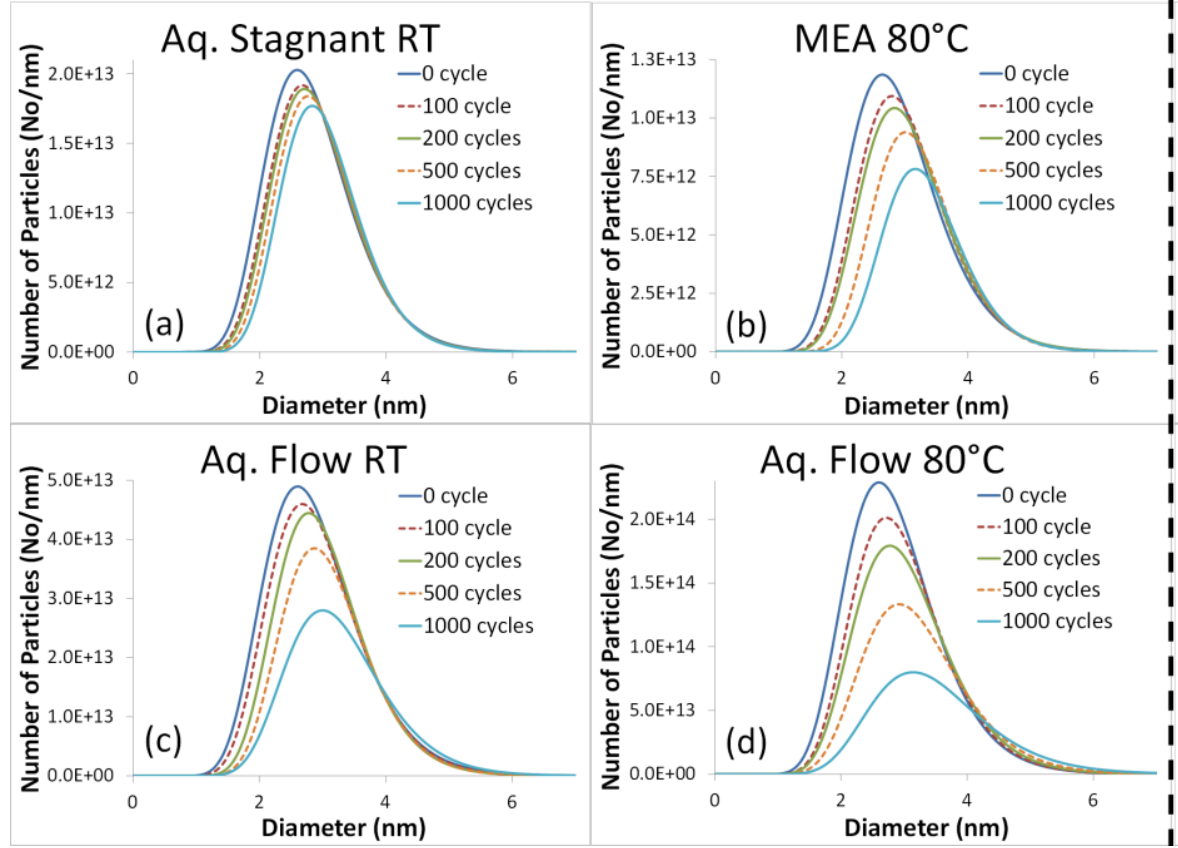

Triangle Wave $(0.6-1.0 \mathrm{~V})$

MEA $80^{\circ} \mathrm{C}$

b)

A -0 cycle

-200 cycles

--500 cycles

-1000 cycles

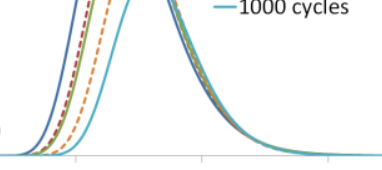

2

Diameter $(\mathrm{nm})$

(e)

MEA $80^{\circ} \mathrm{C}$
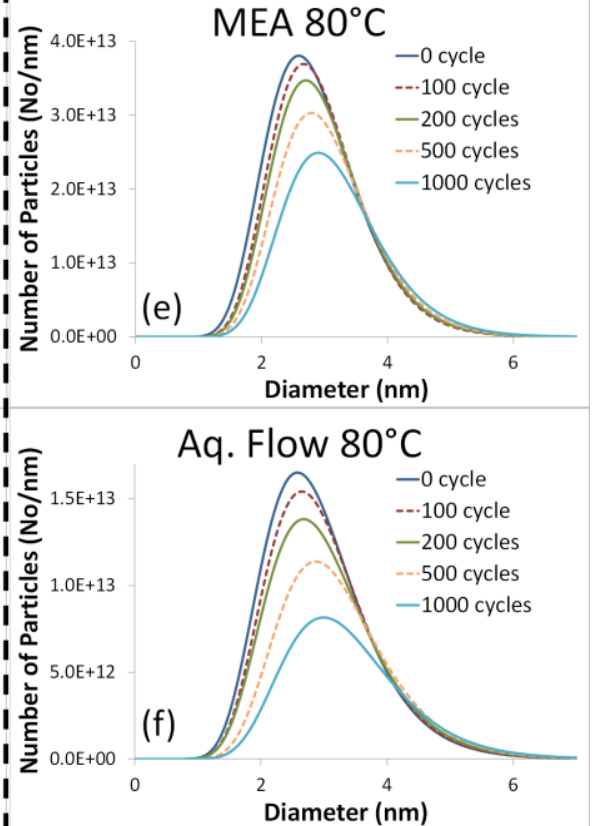

Fig. 2. Particle size distributions for the initial 0 cycles (before cycling), after 100, 200, 500, and 1000 cycles for (a) the aqueous stagnant RT cell, (b) the MEA $80^{\circ} \mathrm{C}$ cell, (c) the aqueous flowthrough RT cell, and (d) the aqueous flow-through $80^{\circ} \mathrm{C}$ cell with a square potential cycling profile. Particle size distributions for the initial 0 cycles (before cycling), after 100, 200, 500, and 1000 cycles for (e) the MEA $80^{\circ} \mathrm{C}$ cell and (f) the aqueous flow-through $80^{\circ} \mathrm{C}$ cell with a triangle potential cycling profile. 


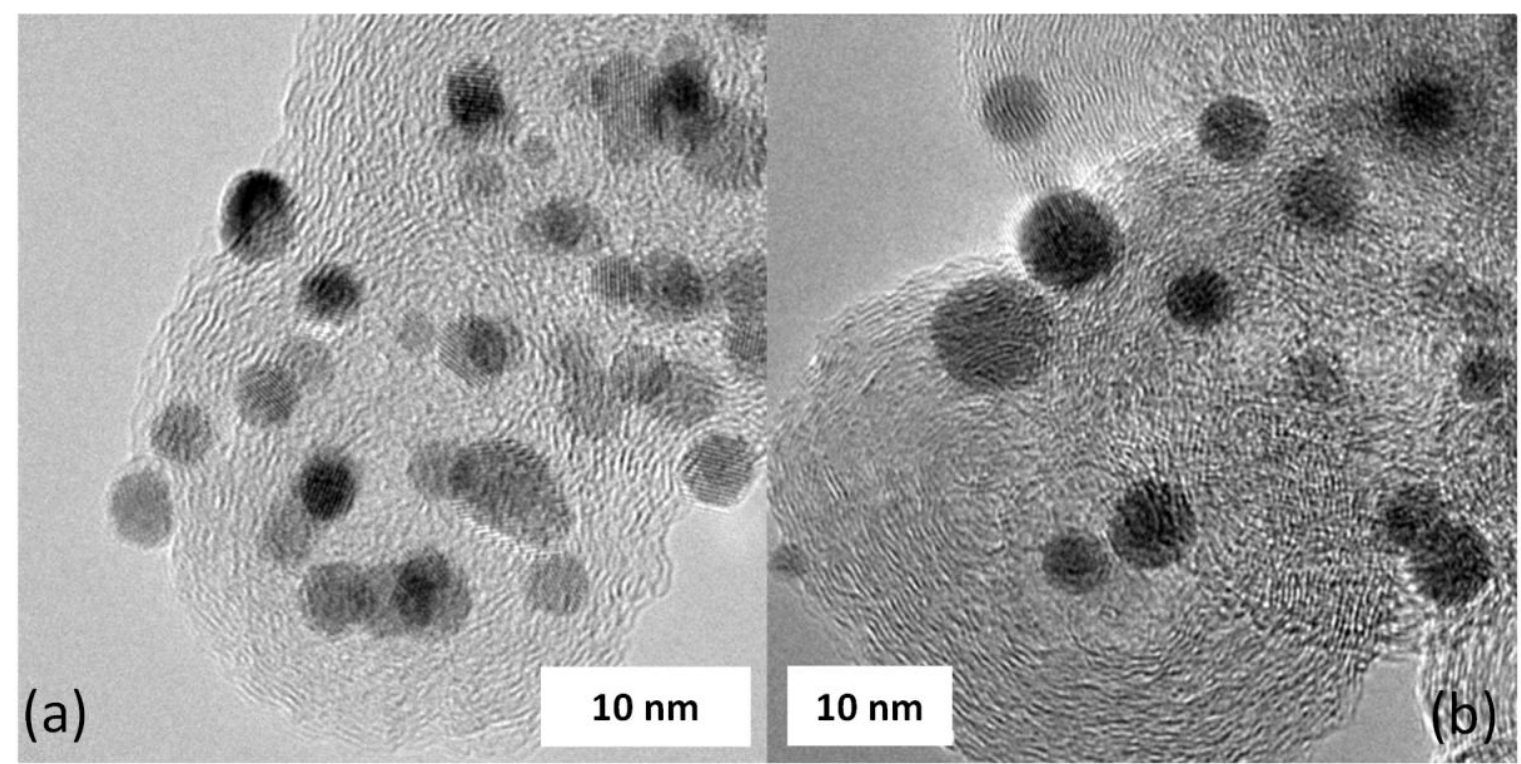

Fig. 3. Representative TEM images for (a) the pristine catalyst powder and (b) the MEA $80^{\circ} \mathrm{C}$ cell after 1500 square potential cycles. 


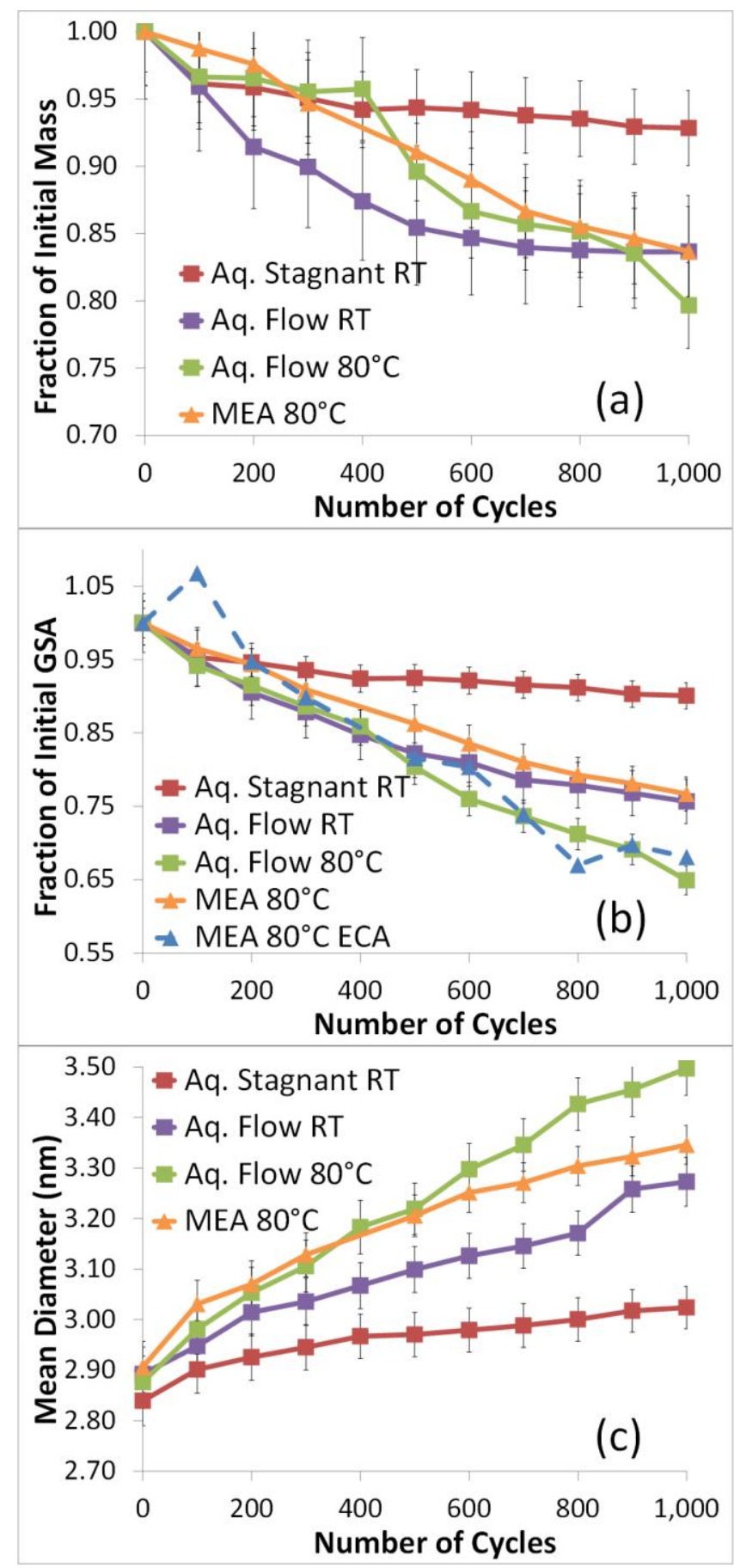

Fig. 4. (a) Fraction of the initial mass, (b) fraction of the initial geometric surface area (ASAXSdetermined), and (c) the mean diameter increase as a function of number of square wave cycles for the aqueous stagnant RT, MEA $80^{\circ} \mathrm{C}$, aqueous flow-through RT, and aqueous flow-through $80^{\circ} \mathrm{C}$ cells. Also included in (b) is the ECA of the MEA $80^{\circ} \mathrm{C}$ cell. 
Fig. 5. Percent of initial mass lost below the CPD, above the CPD, and overall as a function of potential cycling for (a) aqueous stagnant RT, (b) MEA $80^{\circ} \mathrm{C}$, (c) aqueous flow-through RT, and (d) aqueous flow-through $80^{\circ} \mathrm{C}$ cells with square wave potential cycling and for the (e) MEA $80^{\circ} \mathrm{C}$ and (f) aqueous flow-through $80^{\circ} \mathrm{C}$ cells with triangle wave potential cycling. 

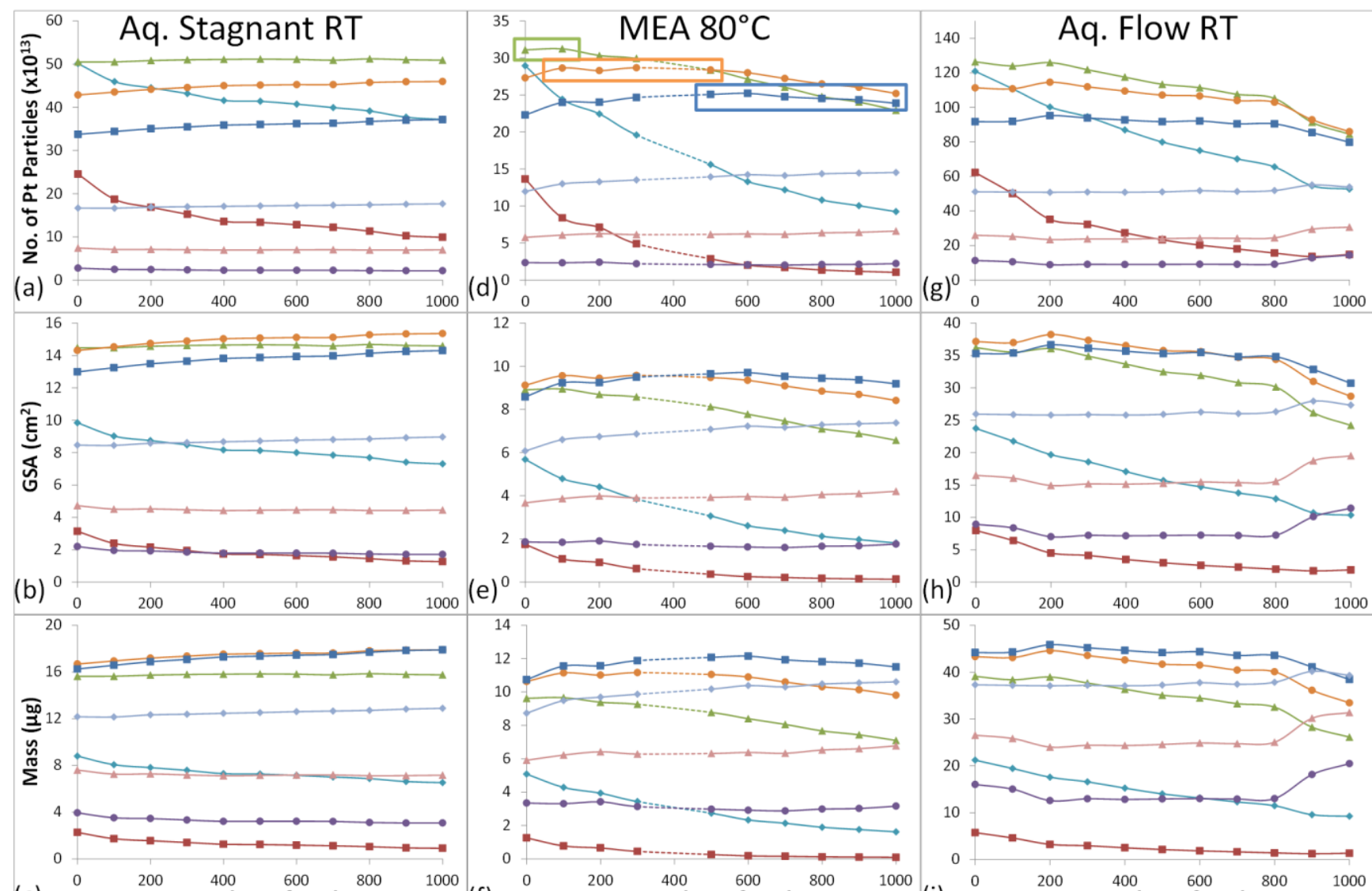

(c) Number of Cycles (f)
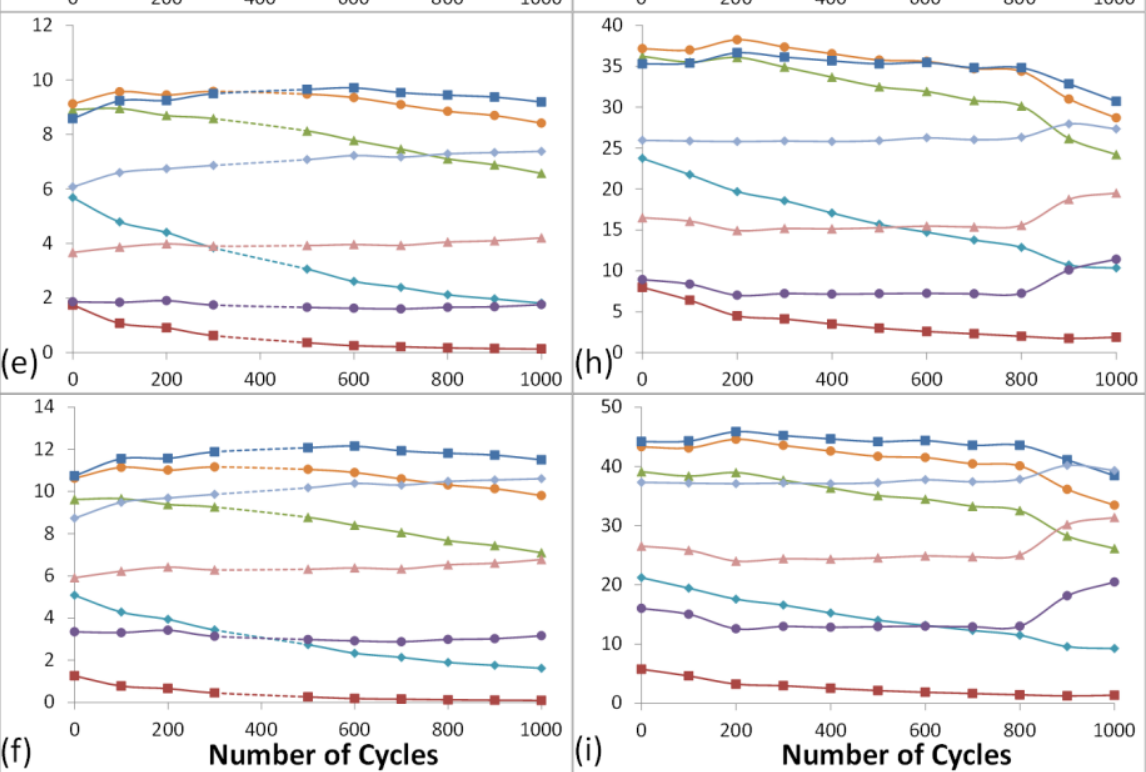
$\rightarrow 2.0 \mathrm{~nm} \nrightarrow 2.5 \mathrm{~nm} \star 3.0 \mathrm{~nm}$

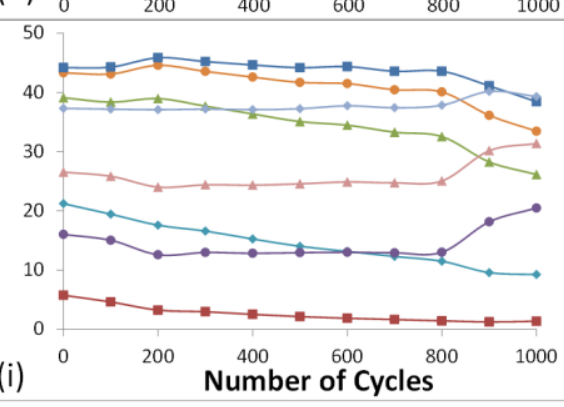

Number of Cycles

Fig. 6. The number of Pt particles, GSA, and mass as a function of the number of square wave cycles for eight different particle diameters $(2.0 \pm 0.02-5.0 \pm 0.02 \mathrm{~nm})$ for the (a-c) aqueous stagnant RT, (d-f) MEA $80^{\circ} \mathrm{C}$, and (g-i) aqueous flow-through RT experiments. Rectangles in (d) indicate CPD. 


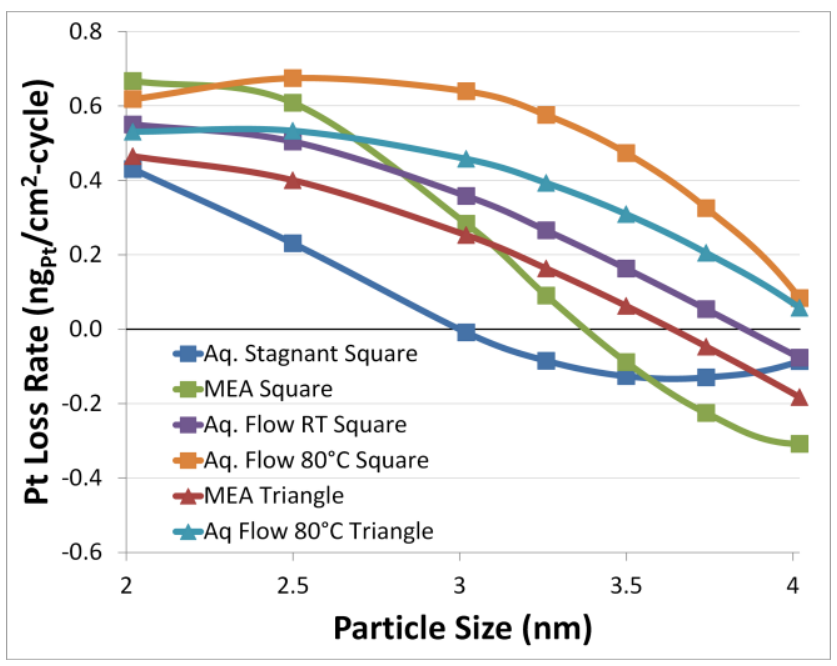

Fig. 7. Pt loss rates as a function of particle size $( \pm 0.02 \mathrm{~nm})$ after 1000 potential cycles for the aqueous stagnant RT, MEA $80^{\circ} \mathrm{C}$, aqueous flow-through RT, and aqueous flow-through $80^{\circ} \mathrm{C}$ cells for both square and triangle wave potential cycling. 


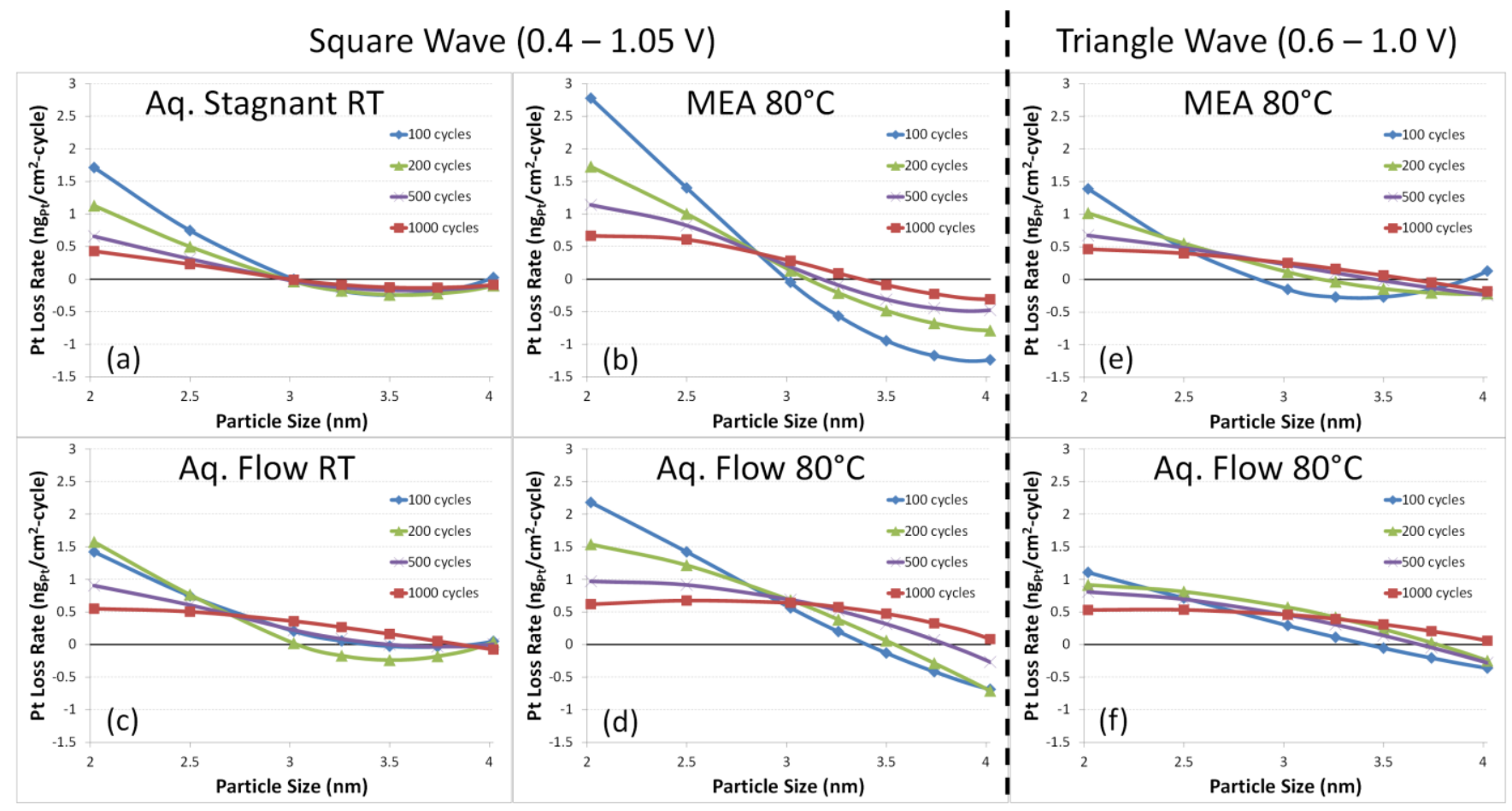

Fig. 8. Pt loss rates as a function of particle size $( \pm 0.02 \mathrm{~nm})$ after $100,200,500$, and 1000 potential cycles for the (a) aqueous stagnant RT, (b) MEA $80^{\circ} \mathrm{C}$, (c) aqueous flow-through RT, and (d) aqueous flow-through $80^{\circ} \mathrm{C}$ cells with square wave potential cycling and for the (e) MEA $80^{\circ} \mathrm{C}$ and (f) aqueous flow-through $80^{\circ} \mathrm{C}$ cells with triangle wave potential cycling. 
1

Table 1. Summary of results of potential cycling experiments after 1000 potential cycles.

\begin{tabular}{|c|c|c|c|c|c|c|}
\hline $\begin{array}{c}\text { Experimental } \\
\text { Environment/ } \\
\text { Cycling } \\
\text { Profile* }\end{array}$ & $\begin{array}{c}\text { ASAXS- } \\
\text { determined } \\
\text { Mean } \\
\text { Diameter } \\
\text { Increase } \\
(\mathrm{nm})\end{array}$ & $\begin{array}{c}\text { Critical } \\
\text { Particle } \\
\text { Diameter } \\
\quad(\mathrm{nm})\end{array}$ & $\begin{array}{c}\text { Geometric } \\
\text { Surface Area } \\
\text { Loss } \\
(<\mathrm{CPD} ;>\mathrm{CPD}) \\
\text { (\% of Initial } \\
\text { Total GSA) }\end{array}$ & $\begin{array}{c}\text { Mass Loss } \\
(<\mathrm{CPD} ;>\mathrm{CPD}) \\
(\% \text { of Initial } \\
\text { Total Mass })\end{array}$ & $\begin{array}{c}\text { Extent of } \\
\text { Coarsening } \\
(\%)\end{array}$ & $\begin{array}{l}\text { Pt Loss } \\
\text { Rate } \\
\left(\mathrm{ng}_{\mathrm{Pt}} / \mathrm{cm}^{2}\right. \\
\text {-cycle) }\end{array}$ \\
\hline $\begin{array}{c}\text { Aqueous } \\
\text { Stagnant } \\
\text { RT/Square }\end{array}$ & $0.18 \pm 0.07$ & 3.0 & $\begin{array}{c}10 \pm 2 \\
(12 ;-2)\end{array}$ & $\begin{array}{c}7.2 \pm 3 \\
(13 ;-5.8)\end{array}$ & $44 \pm 6$ & $\begin{array}{c}0.082 \\
\pm 0.065\end{array}$ \\
\hline $\begin{array}{c}\text { MEA } \\
80^{\circ} \mathrm{C} / \text { Square } \\
\end{array}$ & $0.44 \pm 0.07$ & 3.4 & $\begin{array}{c}23 \pm 3 \\
(27,-4)\end{array}$ & $\begin{array}{c}16 \pm 4 \\
(23 ;-7)\end{array}$ & $30 \pm 3$ & $\begin{array}{c}0.193 \\
\pm 0.083 \\
\end{array}$ \\
\hline $\begin{array}{c}\text { Aqueous } \\
\text { Flow-Through } \\
\text { RT/Square }\end{array}$ & $0.38 \pm 0.07$ & 3.9 & $\begin{array}{c}24 \pm 4 \\
(26,-2)\end{array}$ & $\begin{array}{c}16 \pm 5 \\
(21 ;-5)\end{array}$ & $24 \pm 4$ & $\begin{array}{c}0.194 \\
\pm 0.084\end{array}$ \\
\hline $\begin{array}{c}\text { Aqueous } \\
\text { Flow-Through } \\
80^{\circ} \mathrm{C} / \text { Square }\end{array}$ & $0.62 \pm 0.07$ & 4.1 & $\begin{array}{c}35 \pm 3 \\
(46 ;-11)\end{array}$ & $\begin{array}{c}20 \pm 4 \\
(30 ;-10)\end{array}$ & $34 \pm 3$ & $\begin{array}{c}0.239 \\
\pm 0.088\end{array}$ \\
\hline $\begin{array}{c}\text { MEA } \\
80^{\circ} \mathrm{C} / \text { Triangle } \\
\end{array}$ & $0.31 \pm 0.07$ & 3.6 & $\begin{array}{c}15 \pm 3 \\
(21 ;-6)\end{array}$ & $\begin{array}{c}7.3 \pm 4 \\
(11 ;-3.7) \\
\end{array}$ & $34 \pm 3$ & $\begin{array}{c}0.087 \\
\pm 0.065 \\
\end{array}$ \\
\hline $\begin{array}{c}\text { Aqueous } \\
\text { Flow-Through } \\
80^{\circ} \mathrm{C} / \text { Triangle }\end{array}$ & $0.45 \pm 0.08$ & 4.1 & $\begin{array}{c}25 \pm 4 \\
(32 ;-7)\end{array}$ & $\begin{array}{c}15 \pm 5 \\
(22 ;-7)\end{array}$ & $31 \pm 4$ & $\begin{array}{c}0.171 \\
\pm 0.079\end{array}$ \\
\hline
\end{tabular}

* Square: 0.4 to $1.05 \mathrm{~V}, 20 \mathrm{sec} /$ cycle; Triangle: 0.6 to $1.0 \mathrm{~V}, 50 \mathrm{mV} / \mathrm{s}$ 
Table 2. Summary of Pt loss and Pt dissolution rates from this work and from literature.

\begin{tabular}{|c|c|c|c|c|c|}
\hline Catalyst & \multicolumn{2}{|c|}{ Conditions } & $\begin{array}{c}\text { Dissolution } \\
\text { Rate } \\
\text { (g/cm²-cycle) } \\
\end{array}$ & $\begin{array}{c}\text { Dissolution } \\
\text { Rate } \\
\text { (g/cm²-sec) }\end{array}$ & Reference \\
\hline \multirow{3}{*}{$\mathrm{Pt} / \mathrm{C}$} & \multirow{3}{*}{$\begin{array}{l}0 \mathrm{~V} \text { to upper limit } \\
\text { shown, } 10 \mathrm{mV} / \mathrm{s} \text {, } \\
\text { modeled, MEA, } \\
50^{\circ} \mathrm{C} \text { Upper limit: }\end{array}$} & $1.0 \mathrm{~V}$ & $3.5 \times 10^{-13}$ & $1.8 \times 10^{-15}$ & \multirow{3}{*}{$\begin{array}{c}\text { Darling } \\
\text { and } \\
\text { Meyers[51] }\end{array}$} \\
\hline & & $1.2 \mathrm{~V}$ & $1.6 \times 10^{-10}$ & $6.7 \times 10^{-13}$ & \\
\hline & & $1.4 \mathrm{~V}$ & $5.0 \times 10^{-10}$ & $1.8 \times 10^{-12}$ & \\
\hline \multirow{3}{*}{$10 \mathrm{wt} \% \mathrm{Pt} / \mathrm{C}$} & \multirow{3}{*}{$\begin{array}{c}0.87 \text { to } 1.2 \mathrm{~V} \text {, square } \\
\text { wave, } 60 \mathrm{sec} \text { period, } \\
\text { MEA }\end{array}$} & $40^{\circ} \mathrm{C}$ & $1.3 \times 10^{-10}$ & $2.2 \times 10^{-12}$ & \multirow{3}{*}{$\begin{array}{l}\text { Bi et } \\
\text { al.[52] }\end{array}$} \\
\hline & & $60^{\circ} \mathrm{C}$ & $2.8 \times 10^{-10}$ & $4.7 \times 10^{-12}$ & \\
\hline & & $80^{\circ} \mathrm{C}$ & $5.0 \times 10^{-10}$ & $8.3 \times 10^{-12}$ & \\
\hline $\mathrm{Pt} / \mathrm{C}$ & $\begin{array}{c}0.6 \text { to } 1.35 \mathrm{~V} \text {, square } \\
\text { wave, } 4 \mathrm{sec} \text { period, } \\
\mathrm{MEA}, \mathrm{Air} / \mathrm{H}_{2}\end{array}$ & $68^{\circ} \mathrm{C}$ & $1.4 \times 10^{-9}$ & $3.5 \times 10^{-10}$ & $\begin{array}{l}\text { Zhang et } \\
\text { al.[53] }\end{array}$ \\
\hline \multirow{3}{*}{$\begin{array}{l}\text { Pt nano-particle } \\
\text { film } \\
(<20-200 \mathrm{~nm} \\
\text { particles })\end{array}$} & \multirow{3}{*}{$\begin{array}{l}0 \mathrm{~V} \text { to upper limit } \\
\text { shown, } 10 \mathrm{mV} / \mathrm{s} \text {, } \\
100 \text { cycles, } 0.5 \mathrm{M} \\
\mathrm{H}_{2} \mathrm{SO}_{4}, 25^{\circ} \mathrm{C}, \\
\text { EQCM. Upper limit: }\end{array}$} & $1.0 \mathrm{~V}$ & $1.6 \times 10^{-11}$ & $8.0 \times 10^{-14}$ & \multirow{3}{*}{$\begin{array}{l}\text { Sugawara } \\
\text { et al.[50] }\end{array}$} \\
\hline & & $1.2 \mathrm{~V}$ & $1.4 \times 10^{-10}$ & $6.0 \times 10^{-13}$ & \\
\hline & & $1.4 \mathrm{~V}$ & $4.5 \times 10^{-10}$ & $1.6 \times 10^{-12}$ & \\
\hline $5 \mathrm{wt} \% \mathrm{Pt} / \mathrm{C}$ & $\begin{array}{c}0.05 \text { to } 1.4 \mathrm{~V}, \\
45 \mathrm{mV} / \mathrm{sec}, 2845 \\
\text { cycles, } 1 \mathrm{M} \mathrm{H}_{2} \mathrm{SO}_{4}\end{array}$ & & $5.6 \times 10^{-11}$ & $9.4 \times 10^{-13}$ & $\begin{array}{l}\text { Kinoshita } \\
\text { et al.[39] }\end{array}$ \\
\hline \multirow{4}{*}{$40 \mathrm{wt} \% \mathrm{Pt} / \mathrm{C}$} & \multirow{4}{*}{$\begin{array}{c}0.4 \text { to } 1.05 \mathrm{~V}, 20 \mathrm{sec} \\
\text { period, } 1000 \text { cycles }\end{array}$} & \begin{tabular}{|c}
$0.1 \mathrm{M} \mathrm{HClO}_{4}$, \\
$80^{\circ} \mathrm{C}$, \\
stagnant \\
\end{tabular} & $8.2 \times 10^{-11}$ & $4.1 \times 10^{-12}$ & \multirow{4}{*}{ This work } \\
\hline & & $\begin{array}{c}\mathrm{MEA}, 80^{\circ} \mathrm{C} \\
\mathrm{N}_{2} / \mathrm{H}_{2} \\
\end{array}$ & $1.93 \times 10^{-10}$ & $9.65 \times 10^{-12}$ & \\
\hline & & $\begin{array}{l}0.1 \mathrm{M} \mathrm{HClO}_{4} \text {, } \\
25^{\circ} \mathrm{C} \text {, flow }\end{array}$ & $1.94 \times 10^{-10}$ & $9.70 \times 10^{-12}$ & \\
\hline & & $\begin{array}{c}0.1 \mathrm{M} \mathrm{HClO}_{4}, \\
80^{\circ} \mathrm{C} \text {, flow }\end{array}$ & $2.39 \times 10^{-10}$ & $1.2 \times 10^{-11}$ & \\
\hline \multirow{2}{*}{$40 \mathrm{wt} \% \mathrm{Pt} / \mathrm{C}$} & \multirow{2}{*}{$\begin{array}{c}0.6 \text { to } 1.0 \mathrm{~V} \\
50 \mathrm{mV} / \mathrm{s}, 1000 \\
\text { cycles }\end{array}$} & $\begin{array}{c}\mathrm{MEA}, 80^{\circ} \mathrm{C} \\
\mathrm{N}_{2} / \mathrm{H}_{2}\end{array}$ & $8.7 \times 10^{-11}$ & $5.4 \times 10^{-12}$ & \multirow{2}{*}{ This work } \\
\hline & & $\begin{array}{c}0.1 \mathrm{M} \mathrm{HClO}_{4}, \\
80^{\circ} \mathrm{C} \text {, flow }\end{array}$ & $1.71 \times 10^{-10}$ & $1.07 \times 10^{-11}$ & \\
\hline
\end{tabular}

